\title{
1 Small-scale deformation of an Arctic sea ice floe detected by GPS \\ 2 and satellite imagery
}

3

4 Byongjun Hwang ${ }^{*}$, Pedro Elosegui ${ }^{2,3}$, and Jeremy Wilkinson ${ }^{4}$

5

6

$7 \quad{ }^{1}$ Scottish Association for Marine Science, Oban, Argyll, PA37 1QA, UK

$8 \quad{ }^{2}$ Institute of Marine Sciences (ICM-CSIC), Barcelona, Spain

$9{ }^{3}$ Massachusetts Institute of Technology, Haystack Observatory, Westford, MA, USA

$10{ }^{4}$ British Antarctic Survey, High Cross, Madingley Road, Cambridge, CB3 OET, UK

11

12

13

$14{ }^{*}$ Corresponding author

15 Tel: +44-1631-559-428; Fax: +44-1631-559-001

16 E-mail addresses: phil.hwang@sams.ac.uk

17

1

(C) 2015. This manuscript version is made available under the Elsevier user license http://www.elsevier.com/open-access/userlicense/1.0/ 


\section{Abstract}

2 Small-scale ( 100 to $200 \mathrm{~m}$ ) deformations of an Arctic sea ice floe were detected

3 from multiple GPS-equipped buoys that were deployed on the same ice floe. Over a

4 nine-month period three deformation events were recorded. At each case the event

5 was of limited duration, each lasting less than a day. The events were highly

6 compressive in nature with the area occupied by the buoy array decreasing by over

7 half of the original area. The strain rate during the deformation, of the order of $10^{-5}$

$8 \mathrm{~s}^{-1}$, is about three orders of magnitude larger than previous estimates for brittle

9 fracturing for cracks of about $100 \mathrm{~m}$ in length. On the 2-day time scale, the strain

10 rate became too small and none of the deformation events could be detected. This

11 suggests that satellite data with longer time scales may significantly underestimate

12 the amount of intermittent, small-scale brittle failure of total deformation. Taken as

13 a whole, our results show the influence that large-scale wind stress can have on

14 small-scale deformation. However, it is important to note that the impact of large-

15 scale wind stress is also dependent on the properties of sea ice as well as on the

16 spatial and temporal evolution of the underlying forces that influence the fracturing

17 process.

\section{1. Introduction}

20 Arctic sea ice is in a constant state of deformation (e.g., Kwok and Sulsky, 2010).

21 Under the action of external forces (primarily winds and ocean currents), a

22 continuous sheet of sea ice can be deformed to form a number of ice features such as

23 leads, ridges, and rubble fields. Interestingly, a number of authors have shown that

24 the rate of deformation of Arctic sea ice has increased in response to the recent

25 decrease in sea ice extent and thickness (e.g., Rampal et al., 2009; Zhang et al., 2012),

26 particularly so after the record minimum of ice extent in 2007 (Kwok and

27 Cunningham, 2012).

28 Previous studies using satellite and drifting buoy data indicate that sea ice 29 deformation is highly heterogeneous, localized, intermittent, and displays

30 multifractal, scale-invariant behaviour (e.g., Marsan et al. 2004; Rampal et al., 2008).

31 Ice deformation is not only dependent on external forcing but is also a function of

32 sea ice compactness, strength, and heterogeneity. Compactness is a measure of ice 
1 concentration. In winter, ice concentration in the Arctic Ocean is close to $100 \%$,

2 while in spring and summer ice concentration can decrease significantly. Ice

3 strength is a difficult variable to monitor but it can be estimated from the ice

4 temperature profile (brine volume) and ice type (Kovacs, 1996). The brine volume,

5 which is a function of temperature and salinity, increases with temperature. For

6 example, warm ice has a high volume of liquid brine and is thus weaker than cold

7 ice. Heterogeneity relates to the horizontal distribution of ice types, cracks, leads

8 and refrozen melt ponds. As these properties vary spatially and temporally this,

9 important parameter is difficult to estimate.

10 For the brittle failure of sea ice, Marsan et al. (2004) obtained a strain rate of

$11 \quad 10^{-4} \mathrm{~s}^{-1}$ and estimated, at the 3-day time scale, that brittle failure would occur at

12 relatively small percentage of total deformation (about $0.2 \%$ of total area). Schulson

13 (2004), on the other hand, estimated that the transition from ductile deformation to

14 brittle failure occurs at a strain rate of $10^{-8} \mathrm{~s}^{-1}$. Such low transitional strain rates can

15 be attributed to a relatively high resistance to creep (Schulson, 2004). This wide

16 range of ductile-to-brittle transitional strain rates (ranging from $10^{-8} \mathrm{~s}^{-1}$ to $10^{-4} \mathrm{~s}^{-1}$ )

17 may be due to different length scales for the stress concentrators (i.e., cracks and

18 leads).

19 Using a combined approach involving satellite imagery and laboratory

20 experiments, Schulson (2004) showed that brittle failure could occur under

21 "moderate" biaxial compression. Such compression produced fracture features in

22 well-organized patterns (spanning from millimetre to hundreds of kilometres), as

23 opposed to random patterns associated with thermal cracks. These types of

24 fractures are called "brittle" compressive shear faults and generally occur when new

25 ice that is located between thicker ice floes grows rigid enough to create a

26 mechanical continuum (Richter-Menge and Elder, 1998).

$27 \quad$ Hutchings et al. (2011), using an array of GPS drifters spanning distances

28 between 10-140 km, also found sea ice deformation to follow a multi-fractal

29 behaviour (Rampal et al. 2008). When they examined the spectral properties of

30 deformation (which represents the full scaling behaviour, as opposed to Marsan et

31 al. (2004), who considered the scaling properties of sea ice deformation), they found

32 no apparent universal scaling law for ice deformation that could be applied between

$33 \quad 10-70 \mathrm{~km}$. This implies that the largest energy dissipation occurs at small spatial

34 scales (e.g., say km scale, or less), as well as decoupling from large-scale 
1 atmospheric wind forcing. This view is supported by Herman and Glowacki (2012),

2 Geiger et al. (2000), Walter and Overland (1993), and others. However, the scaling

3 of deformation at smaller spatial scales remains unresolved, largely for lack of

4 measurements of transient and higher-stress episodes (e.g., Richter-Menge and

5 Elder, 1998; Richter-Menge et al., 2002).

We present observations of several discrete deformation events as captured

7 by a tight network of GPS-equipped drifters deployed on a single ice floe. The

8 network spanned less than $200 \mathrm{~m}$. Over the 9-month duration of this study, a total of

9 three major deformation events occurred. They were clustered over a 10-day

10 period, but each event lasted a day or less. Consequently, the structure of this paper

11 is organized to address two major questions:

12 (1) What is the character of Arctic sea ice deformation at sub-km scales?

(2) How does small-scale deformation connect to large-scale atmospheric forcing?

To address these questions, we present the field observation program in section 2 , describe the data and data analysis in section 3 , chronicle the three deformation events in section 4, and discuss the results in section 5 .

\section{Background and fieldwork}

\subsection{Environment and region}

20 On 13 September 2012, sea ice extent in the Arctic Ocean reached its lowest point

21 since routine satellite observations started in $1978,3.4 \times 10^{6} \mathrm{~km}^{2}$, a drop of about a

22 million square kilometers from the previous minimum, in 2007 (Parkinson and

23 Comiso, 2013). This dramatic loss of sea ice was most evident in the Chukchi Sea

24 and Beaufort Sea, where by mid-August the sea ice edge had retreated beyond $80^{\circ} \mathrm{N}$

25 (Parkinson and Comiso, 2013; also our field observations). The causes of summer

26 sea ice retreat are complex and have been attributed to multiple factors, including

27 overall thinning of the ice and loss of thick multi-year ice (MYI) (Kwok and

28 Rothrock, 2009), a significant storm in early August in the region (Simmonds and

29 Rudeva, 2012), and mechanical breakup and melting of sea ice due to enhanced

30 mixing in the upper ocean (Zhang et al., 2013).

31 Our team joined the International Arctic Ocean Research Expedition 2012 led

32 by the Korea Polar Research Institute (KOPRI) onboard the icebreaker research 
1 vessel (IBRV) Araon. The expedition originally planned to cover the region between

2 the northern Chukchi Sea and the border of East Siberian Sea. However, substantial

3 ice loss in the region prompted the cruise to divert northward in search of suitable

4 ice of adequate sea ice concentration (SIC) for buoy deployment operations. Guided

5 by passive-microwave SIC maps and helicopter reconnaissance surveys, a

6 deployment region was selected in the region bordering the East Siberian Sea and

7 the northern Chukchi Sea $\left(81^{\circ} 40.38^{\prime} \mathrm{N}\right.$ and $174^{\circ} 15.56^{\prime} \mathrm{E}$; Figure $\left.1 \mathrm{a}\right)$. The SIC at the

8 time of deployment was more than $70 \%$ and comprised a melange of ice floes of

9 various sizes, from tens of meters to tens of kilometres (Figure 1). Larger ice floes

10 mostly consisted of first-year ice (FYI) pans embedded with smaller pieces of MYI

11 that could be recognized by its higher freeboard, undulating topography, and the

12 presence of blue-like melt ponds on their surface.

\section{2.2. Ice floe description}

14 The ice floe for the buoy deployment was located about $10 \mathrm{~km}$ into the pack from

15 the broken ice edge (Figure 1b). The selected square-shaped floe had sides of

16 approximately $2 \mathrm{~km}$ (Figure 1c). It comprised of different ice types frozen together,

17 and contained a high percentage of melt ponds. Araon broke a path towards the

18 centre of the floe, and eventually moored in a region of level FYI for the duration of

19 the deployment (Figure 1d). After deployment Araon left via the same route as she

20 entered. The track of the ship can be seen as a faint line running from the ship to the

21 bottom right-hand side of Figure 1c.

22 The area adjacent to the moored ship (about $100 \mathrm{~m}$ in radius, green circle in

23 Figure 1c) was level ice and contained very few melt ponds. Ice thickness in this

24 region was about $1 \mathrm{~m}$. Bulk ice salinity measured from an ice core (1.1-m thick)

25 taken nearby the ship was $1.7 \pm 1.0 \mathrm{psu}$, ranging from about $0.2 \mathrm{psu}$ in the top $0.3 \mathrm{~m}$

26 to about $2.8 \mathrm{psu}$ in the bottom $0.4 \mathrm{~m}$. Ice temperature was isothermal at around 0

$27{ }^{\circ} \mathrm{C}$. These conditions resemble typical salinity profile of FYI after melt-water flushing

28 during summer melt (Petrich and Eicken, 2010). The temperature and salinity as

29 well as the smoothness, thickness, and levelness of this part of the ice suggest that

30 the floe was FYI, formed during the previous winter. Surrounding the FYI lay several

31 pieces of MYI with blue-looking melt ponds (i.e., closed, melt ponds not connected to

32 the underlying ocean). At the interface between the MYI and the FYI a chain of melt

33 ponds and small ridging existed (Figure $1 \mathrm{~d}$ and field observation). 


\subsection{Deployment of buoys}

2 Three types of buoys were deployed on this floe. A short description of each system

3 can be found below, and a summary of the deployment and sampling configurations

4 can be found in Table 1.

5 (1) The SATICE system is an ice buoy equipped with a geodetic-quality GPS

6 receiving system operated continuously and providing $\mathrm{cm}$-level position estimates.

7 A SATICE buoy also includes a variety of complementary geophysical sensor

8 providing a range of atmospheric, cryospheric, and oceanographic observations

9 (Elosegui et al., 2012). Within this paper we refer to these buoys using the prefix SI.

10 The model numbers deployed were SI03 and SI04.

11 (2) Sea ice mass balance (IMB) buoys were equipped with a string of

12 thermistors, and a standard-precision (few meters; see below) GPS receiver. They

13 had either (a) a 5-m long chain with 240 thermistor sensors at 2-cm interval or (b) a

14 10-m long chain with the upper $5 \mathrm{~m}$ with 2 -cm interval ( 240 sensors) and the

15 bottom $5 \mathrm{~m}$ with 50 -cm intervals between sensors ( 10 sensors). Detailed

16 description of these IMBs is available elsewhere (Jackson et al. 2013). Within this

17 paper we refer to these buoys using the prefix KP. The model numbers deployed

18 were KP01 through KP08.

19 (3) Seasonal ice mass balance buoy (SIMB) is a floatable IMB that is designed to

20 survive through the summer melt season. They have air temperature and

21 barometric pressure sensors, under ice sounder (distance to the ice bottom), snow

22 sounder (distance to the snow surface), under ice pressure sensor, and temperature

23 string. Detailed description can be found elsewhere (Polashenski et al. 2011). The

24 model number deployed was 2010I.

25 The buoy deployments were scheduled for a two-day period spanning from 13 to

26 14 August 2012. The description in this section refers to local Alaskan time (UTC - 9

$27 \mathrm{~h}$ ), to match the circadian rhythm of the cruise log annotations. On the first day of

28 deployment (August 13), the weather and visibility were good and a number of

29 systems were deployed, however thick fog rolled in overnight and the next morning

30 (August 14) the visibility was very poor. With conditions barely improving and our

31 deployment window shrinking, it was decided that the remaining systems should be

32 deployed relatively close to the ship, but on different ice types, i.e., a combination of

33 FYI and MYI. In this way we could investigate the differential movement between 
1 the deployed systems should the floe deform, as well as the differential melt

2 processes that occur within a single floe comprised of different ice types.

3 On August 13, the first set of buoys was deployed at the starboard side of the 4 ship (about $20 \mathrm{~m}$ from the ship) on the smooth FYI (Table 1). They included one 5 SATICE (SI03), two IMBs (KP01 and KP08), and one SIMB (2010I). All four buoys 6 were deployed relatively close together (Figure 1d). In order for the melt processes

7 measured by KP01 to be analyzed in conjunction with the complementary data from

8 SI03 the separation between buoys SI03 and KP01 was particularly close, about $6 \mathrm{~m}$.

9 At a distance of around $20 \mathrm{~m}$ from these two systems, buoys KP08 and 2010I were

10 deployed for inter-calibration purposes. The ice thickness and snow depth at these

11 deployment locations were similar, 1.09-1.28 $\mathrm{m}$ and 0.07-0.10 m, respectively

12 (Table 1). In the evening of August 13, a helicopter photographic survey was

13 conducted for one hour. The aerial photo shown in Figures $1 \mathrm{c}-1 \mathrm{~d}$ was taken during 14 this survey.

15 On the morning of August 14, three buoys were deployed at the portside of the 16 ship, at about $20 \mathrm{~m}$ from the ship (Figure 1d). These were SATICE (SI04) and two

17 IMBs (KP02 and KP07). Buoys SI04 and KP02 were also deployed within $6 \mathrm{~m}$ of each

18 other, but KP07 was deployed at about $15 \mathrm{~m}$ distance from SI04 at the edge of a

19 small melt pond. The ice thickness and snow depth at those deployment sites varied 20 very little at around $1.04 \mathrm{~m}$ and $0.11 \mathrm{~m}$, respectively (Table 1 ).

21 In the afternoon of August 14 two buoys (KP03 and KP04) were deployed on the 22 MYI; lying at about 100-150 $\mathrm{m}$ from the starboard side of the ship (Figure 1d). The 23 ice thickness at the KP03 site was $3.17 \mathrm{~m}$, which was much thicker than the smooth 24 FYI where previous buoys deployed (Table 1). Additional drill-hole thickness 25 measurements nearby to the KP03 site confirmed this thickness, with ice 26 thicknesses up to about $4 \mathrm{~m}$ being measured. The location of KP04 was chosen to be 27 at the edge of a small melt pond to try to capture the thermal evolution of this MYI 28 melt pond. Although it was clearly the same piece of MYI the ice thickness, $1.01 \mathrm{~m}$, 29 was much thinner at the KP04 than at the KP03 location. Enhanced thinning at the 30 KP04 site may be seen by the darker tones in the snow cover near KP04 (see Figure 31 1d).

32 For the last two buoys (KP05 and KP06) we selected the MYI located about 150 $33 \mathrm{~m}$ from the ship, and about $10^{\circ}$ from the ship heading (Figure $1 \mathrm{~d}$ ). The locations of 34 KP05 and KP06 were chosen to sample two different ice thicknesses while lying on 
1 the same piece of MYI, i.e., KP05 was deployed in the 3.0-m thick ice while KP06 was

2 deployed in 1.4-m thick ice (Table 1). This highlights the differential melt processes

3 that occur with MYI.

4 Table 1 contains the details of GPS sampling rates, parameters logged, and 5 operational status of the buoys (as of this writing). Upon leaving the floe all buoys

6 were functioning correctly. However, KP06 and KP01 failed prematurely on August

723 and September 14, respectively, and a series of major deformation events in

8 December (described in section 4) shortened the lives of SI03, SIMB-2010I, KP05,

9 and KP07. Only five buoys (SI04, KP02, KP03, KP04, and KP08) survived these

10 deformation events and all KP-IMB thermistor chains were compromised or lost.

11 Among the buoys that survived the deformation, KP02 was located only about $6 \mathrm{~m}$

12 from SI04, near the center of the FYI floe, KP08 was located in FYI, near the FYI/MYI

13 boundary, and KP03 and KP04 were deployed in MYI (Figure 1d). Because this study

14 focuses on GPS-based positioning, KP02 will not be further utilized as its short

15 distance to SI04 is within the 1-sigma position error of the former (see below).

16 Furthermore, because the GPS position estimates of SI04 are more than two orders

17 of magnitude better than those of the KPs with regard to both precision (few $\mathrm{cm}$

18 versus few $\mathrm{m}$; see below) and sampling rate ( $30 \mathrm{~s}$ versus $1 \mathrm{hr}$ ), in this study SI04

19 acts as the position/velocity ground-truthing anchor for the KP-IMB network (see

20 below). Given these details, our floe deformation analysis will use the positioning

21 data from four buoy systems: SI04, KP03, KP04, and KP08 (highlighted in bold in

22 Table 1).

\section{3. GPS data, methods, and error assessment}

24 We obtained position information with three different observing platforms, each

25 using a different type of GPS receiving system (see Table 1). The first platform, a

26 SATICE buoy, was equipped with a geodetic-quality GPS system. Data processing of

27 dual-frequency GPS (carrier-phase) observables using the high-rate GPS technique,

28 and the resulting position and error estimates are described in Elosegui et al.

29 (2006). Of relevance to this study, position estimates for SI04 were obtained once

30 every $30 \mathrm{~s}$ with $\mathrm{cm}$-level precision. On the other hand, the two other platforms, i.e.,

31 the IMBs and the SIMB buoys, were equipped with single-frequency code GPS

32 receivers. The same GPS system was used in the 8 IMB (KP) buoys, but different, in

33 turn, from the SIMB GPS unit. Position estimates from the single-frequency systems 
1 were obtained once per hour (though other sampling times were also used; see

2 Table 1), with a precision that is 2-3 orders of magnitude worse than the geodetic-

3 quality GPS counterpart, or at the few-m level. Since the focus of this study is the use

4 of position estimates from the combined GPS network to measure floe deformation,

5 we turn next to the data, methods, and error assessment with emphasis on the low-

6 precision GPS systems.

$7 \quad$ GPS data in applications that involve low-precision receivers such as those in

8 the IMB and SIMB buoys typically refers to position estimates, which are readings

9 provided directly by the receiver. In contrast, GPS data from geodetic-quality

10 systems refers to the carrier-phase (raw) observables, which require data post-

11 processing using precise GPS satellite products and state-of-the-art geophysical

12 models and optimal estimation methods to obtain high-precision position estimates.

13 Hereafter, for consistency among GPS systems, we will use GPS data when we refer

14 to position estimates. Although GPS data in these lower-grade receivers are

15 specified to the equivalent of about $10 \mathrm{~cm}$, the precision is significantly worse.

16 Moreover, error estimates are commonly missing, which hampers GPS data editing

17 and validation. Since the scientific focus of this study is floe deformation over small

18 (between 110-250 m) spatial scales using GPS data from a relatively fast-moving

19 (up to about $0.7 \mathrm{~m} / \mathrm{s}$ ) network, error assessment becomes essential.

20 Before assessing the errors, we formed a dataset of horizontal baselines (i.e.,

21 horizontal component of baseline length and baseline orientation) with the data of

22 all IMBs by subtracting the position at each IMB epoch from the corresponding

23 horizontal position of SI04. Theoretically, the position error of each GPS system

24 should be smaller than the baseline error. Therefore, the estimated baseline error

25 should be an upper bound for the GPS error of each system. In practice, SI04 does

26 not contribute to the baseline error because the variance of the IMB GPS data is

27 about $10^{4}$ times larger than the variance of the SI04 data, thus effectively making the

28 latter a "ground-truth" estimate for the IMB GPS data. An additional benefit of using

29 SI04 as baseline reference is that its high-precision data are also high rate, i.e., are

30 estimated here once every $30 \mathrm{~s}$. This is a very desirable feature because it provides a

31 regularized time axis against which the IMB GPS data, whose time stamps may not

32 be regular (see Table 1) nor necessarily coincide with those of SI04, can be aligned

33 prior to forming the baseline dataset without introducing any significant error. 
We used a simple linear model to align the IMB GPS data to the epoch of the

2 closest SI04 estimate. Velocities for the linear model are calculated by

3 differentiating the 30-s position estimates of SI04, thus resulting in velocity errors

4 that are smaller than $1 \mathrm{~cm} \mathrm{~s}^{-1}$. For 30-s sampling, alignment involves epoch

5 differences that are always less than $15 \mathrm{~s}$. Propagating the velocity errors through

6 the linear model thus results in alignment errors that are $\mathrm{cm}$ level, or negligible. It is

7 explicit in the error calculation above that the floe does not rotate appreciably

8 during the time interval involved in the alignment, which is a reasonable

9 assumption. Indeed, it can be easily calculated that for the longest ( $209 \mathrm{~m}$ ) baseline

10 in our network and largest (15 s) time sampling difference between an IMB and

11 SI04, a position error ( $5 \mathrm{~m}$ ) that is commensurate with the error of the IMB GPS data

12 would result from a floe rotation of $329^{\circ}$ per hour, which is unrealistic (see below).

13 Once the linear interpolation had been applied the baseline length (L) and

14 orientation $(\theta)$ of three IMBs (KP03, KP04, and KP08) were calculated relative to

15 SI04. The baseline orientation is defined positive east from north, i.e., clockwise,

16 thus consistent with the definition of a topocentric frame centered on the position of 17 SI04.

To estimate baseline error, we calculated the root-mean-squared (RMS) scatter around the mean length of two baselines, SI04-KP03 and SI04-KP08, for the

21 values are 1.7 and $3.6 \mathrm{~m}$ for baselines SI04-KP03 and SI04-KP08, respectively, while

22 the RMS value for SI04-KP04 was significantly larger, about $8 \mathrm{~m}$ (Figure 2). The

23 difference between baselines seems to be related to GPS sampling rate, among other

24 factors. For example, the GPS sampling rate of KP03 and KP08 in November 2012

25 was set at $12 \mathrm{~h}$, while the GPS sampling rate of KP04 was set at $1 \mathrm{~h}$ (see Table 1 ).

26 Larger RMS for SI04-KP04 can be attributed to the significant number of outliers

27 (Figure 2a), which is not the case when the GPS sampling is $12 \mathrm{~h}$. Similarly, a large

28 number of outliers are present in the KP03 and KP08 data before November 2012

29 when the GPS sampling rate was $1 \mathrm{~h}$. The causes for this are not fully understood. To

30 estimate the baseline error, we remove 3- $\sigma$ outliers and fitted a Gaussian model to

31 the data (Figure 2b). The 1- $\sigma$ (standard deviation) estimates from the Gaussian fit is

$32 \quad 3.7 \mathrm{~m}$, which is commensurate with the values estimated for baselines SI04-KP03

33 and SI04-KP08 for the same period. Thus, we will use an estimated baseline error $\sigma_{\mathrm{L}}$

34 of $5 \mathrm{~m}$ throughout this manuscript. 
The errors for baseline orientation $\sigma_{\theta}$ can be estimated by $\sigma_{\theta}=\sigma_{L} / L$ for each

2 baseline $\mathrm{L}$ and the baseline error $\sigma_{\mathrm{L}}$ of $4 \mathrm{~m}$, i.e., the shorter the baseline becomes the

3 larger the errors. The errors in the area calculation $\sigma_{\mathrm{A}}$ can be estimated by

$4 \quad \sigma_{A}=\frac{1}{2} \sigma_{L}\left(L_{1}^{2}+L_{2}^{2}\right)^{1 / 2}$ the array area formed by two baselines $\mathrm{L}_{1}$ and $\mathrm{L}_{2}$.

\section{4. Results}

6 Figure 3a shows that the baseline length L for SI04-KP03 (blue), SI04-KP04 (green),

7 and SI04-KP08 (red). The scatters mostly remain within the 1- $\sigma$ of the baseline

8 error $\sigma_{\mathrm{L}}$ (shown as dashed lines in the figure) from their deployment in August until

9 a series of deformation events occurred in mid-December. This clearly indicates no

10 deformation of the floe occurred within the summer melt period (August to

11 October), until December 13. There was however significant variability in the

12 rotation (changes in orientation $\theta$ ) of the floe between the deployment and October

13 (Figure 3b). After mid-October the variability in $\theta$ of the buoys decreased

14 significantly. This change from pre-October to post-October is most likely associated

15 with the timing of local freeze-up near the buoy location (see Section 5.1 for the

16 details). It is also interesting to see that during the post-freeze-up phase there is an

17 underlying, slow, clockwise rotation to $\theta$.

18 The most interesting aspect of Figures $3 \mathrm{a}$ and $3 \mathrm{~b}$ is the major shift, or step-

19 change, in L and $\theta$ that occurred in three discrete periods during mid to late

20 December 2012. It is these events, which all occurred within a 10-day period, that

21 are the main focus of this study. The deformation events (D) commenced on

22 December 13 (D13), December 16 (D16), and December 21 (D21). Between each of

23 these deformation events $\mathrm{L}$ and $\theta$ remained relatively constant suggesting that the

24 deformed floe remained in a stable state (Figure 3c). The location of each of the

25 three deformation events (D13, D16, and D21) is labelled in Figures 3c and 3d.

26 The drift track and speed of the floe for the month of December, calculated by

27 differentiating the high-precision position data of SI04 in time, can be seen in Figure

28 4. During this month the floe drifted about $275 \mathrm{~km}$, performing an elliptical shaped

29 drift that eventually transported the floe very close to its initial position at the start

30 of the month (Figure 4). During this time the drift of the floe went through a

31 number of increases and decreases in drift speed with the average speed being 0.10

$32 \mathrm{~m} \mathrm{~s}^{-1}$, a standard deviation of $0.06(\mathrm{~N}=89277)$, and maximum and minimum speed 
1 of about $0.4 \mathrm{~m} \mathrm{~s}^{-1}$ and $0 \mathrm{~m} \mathrm{~s}^{-1}$, respectively. We now briefly summarise the

2 environmental parameters and ice dynamics during these three deformation events.

\subsection{The D13 event}

The first deformation event (D13) occurred between 17:00 UTC on December 13 to 06:00 UTC the following day (December 14), a total of 13 hours. During this 13hour deformation episode the floe drifted at a fairly uniform speed $\left(0.13 \mathrm{~m} \mathrm{~s}^{-1} \pm\right.$ $0.006, \mathrm{~N}=1560)$ and heading $\left(-89.87^{\circ} \pm 5.49, \mathrm{~N}=1560\right)$ (Figure $\left.5 \mathrm{a}\right)$, as calculated from the SI04 data. Meteorological measurements obtained once every $10 \mathrm{~min}$ by SI04 showed that air temperature during this period was fairly constant at $-32.2^{\circ} \mathrm{C}$ $( \pm 0.4, \mathrm{~N}=79$ ) (Figure $5 \mathrm{~b}$ ), the air pressure was dropping slightly at around 994.7 $\mathrm{hPa}( \pm 0.8, \mathrm{~N}=79)$ (Figure $5 \mathrm{c}$ ), and the humidity also remained constant at $76.3 \%$ $( \pm 0.2, N=79$ ) (not shown here).

This deformation event displaced buoys KP03, KP04, and KP08 relative to SI04. KP03 went through anticlockwise rotation of about 20 degree relative to SI04 but with very little change in L between SI04 and KP03 (Table 2). Similar anticlockwise rotation was shown in KP04, but L between SI04 and KP04 was also increased by $22.8 \mathrm{~m}$ (Table 2). In contrast, no significant rotation was observed in KP08, yet the baseline between SI04 and KP08 was stretched by $54.2 \mathrm{~m}$ (Table 2). If we plot the positions of the buoys before and after the event (Figure 6a: before in white, and after in red) the effects of this deformation event become apparent. Essentially, the buoy array rotated in an anticlockwise direction and it became narrower and more elongated. The area change within the outermost array of buoys SI04-KP08-KP04 was $1222 \mathrm{~m}^{2}$ (above area error limit $\sigma_{\mathrm{A}}$ ), reducing from $4797 \mathrm{~m}^{2}$ to $3575 \mathrm{~m}^{2}$ (Table 3). This compression event resulted in an almost 26\% reduction in ice area.

Upon further investigation, it was found that 2010I, which was deployed beside KP08 (within about $5 \mathrm{~m}$ ) moved together, while SI03, deployed about $20 \mathrm{~m}$ away, moved in a different direction (Figure 6d). This decoupled movement between KP08 and SI03, even though they were initially separated by $20 \mathrm{~m}$, highlights the complex nature of sea ice deformation. Interestingly, some of the largest movements occurred in regions that had a high number of melt ponds in summer. It could be that the now refrozen melt ponds represent regions of thinner ice, and thus may provide regions of mechanical weakness that fail under sustained 
1 compression and shear. Local differences in ice strengths may be a plausible

2 explanation for the differential movement of the buoys.

\subsection{The D16 event}

The second deformation event (D16) occurred over an 11-hour period, starting at 20:00 UTC on December 16 and finishing at 07:00 UTC on December 17. During this event the average drift velocity was $0.17 \mathrm{~m} \mathrm{~s}^{-1}( \pm 0.02, \mathrm{~N}=1320)$ although the floe speed decreased slightly during this event (Figure 4 and Figure $5 a$ ). The heading remained almost constant $\left(-42.3^{\circ} \pm 2.9, \mathrm{~N}=1320\right)$ (Figure 4). During this event, there was only slight drop in air temperature $\left(-26.9^{\circ} \mathrm{C} \pm 0.7, \mathrm{~N}=63\right)$ (Figure $5 \mathrm{~b}$ ), the air pressure also dropped slightly $(996.7 \mathrm{hPa} \pm 0.2, \mathrm{~N}=67)$ (Figure $5 \mathrm{c}$ ), and so did the humidity $(79.5 \% \pm 0.4, \mathrm{~N}=67$ ) (not shown here).

The D16 event can be characterized mainly by a slight stretching in the baselines length $(\Delta \mathrm{Ls}, 8-11 \mathrm{~m})$ and rather uniform clockwise rotation of $15-23^{\circ}$. The clockwise nature of the deformation process changed the shape of array. The array became much narrower and was stretched along the baselines direction followed by the previous D13 event, which indicates a relaxation of the ice after the D13 deformation event. Interestingly, this clockwise rotation carried the buoys back towards their position prior to the D13 event (Figure 6e). The decoupled nature of the movement of the buoys shown during the D13 deformation event also occurred during the D16 event. The movement of SI03 was again decoupled from KP08 and 2010I (Figure 6e). Both KP08 and 2020I co-rotated by about 15 degrees clockwise (above the baseline orientation error limit $\sigma_{\theta}$ ), and moved by $12 \mathrm{~m}$, while the location of SI03 remained almost unchanged (within the baseline length error limit $\sigma_{\mathrm{L}}$ ) (Figure 6e). This, again, highlights the non-linear nature of small-scale ice deformation.

\subsection{The D21 event}

The final deformation event, D21, occurred almost exactly 8 days after the first deformation event of the floe, and was by far the most destructive. It started at 18:00 UTC on December 21 and ended at 9:00 UTC on December 22, a total of 15 hours. (The period of D21 event is defined to capture the most dramatic deformation. It should be noted that L increased about $10 \mathrm{~m}(\Delta \mathrm{L})$ after the D21 event and then shrank back over a day after the event.) This event destroyed several of the platforms that were deployed and were operational on the floe. SI03, KP05, 
1 and 2010I were completely destroyed and the ice mass balance component

2 (thermistor chain installed within the ice) of buoys KP03, KP06, KP07, and KP08

3 were lost, but the GPS component of these buoys continued to work (see Table 1).

4 Miraculously, only SI04 did not suffer any loss of sensors although it was deployed

5 very close to KP07 (within $6 \mathrm{~m}$ ), who also lost its mass balance chain.

6 The environmental parameters surrounding the D21 event are particularly

7 interesting. A significant drop in surface pressure, by almost $30 \mathrm{hPa}$ (Figure 5c), was

8 accompanied by a corresponding rise in air temperature and humidity (Figure 5b),

9 indicating a passage of a low pressure system at the buoy location. The air

10 temperature rose very quickly from $-31^{\circ} \mathrm{C}$ at $18: 06 \mathrm{UTC}$ on December 21 to $-21^{\circ} \mathrm{C}$ at

11 09:06 UTC on December 22, and by the end of the day the temperature rose almost

12 to $-8^{\circ} \mathrm{C}$ (Figure $5 \mathrm{~b}$ ). During this time the air pressure dropped significantly from

$131031.5 \mathrm{hPa}$ at the start of the event to $1015.1 \mathrm{hPa}$ at the end of the event (Figure 5b),

14 and the humidity was also increased from $76.7 \%$ to $82.2 \%$ (not shown here).

15 These represent some of the largest changes the SI04 system recorded between

16 August 2012 and the end of May 2013.

17 In the days prior to D21 the floe performed two very tight turnings in the 18 drift pattern (in direction of almost $300^{\circ}$ ) (Figure 4). The last change in direction

19 occurring less than 12 hours before the deformation commenced. During the

20 deformation period the drift direction remained constant at $-67^{\circ}( \pm 4)$. However, the

21 drift speed of the floe accelerated, increasing from near $0.1 \mathrm{~m} \mathrm{~s}^{-1}$ to over $0.3 \mathrm{~m} \mathrm{~s}^{-1}$ at

22 the end of the event (Figure 4 and Figure 5a). The average drift speed during D21

23 was remarkably fast at $0.25 \mathrm{~m} \mathrm{~s}^{-1}( \pm 0.07)$.

24 During this 15-hour deformation event we witnessed a catastrophic failure of

25 the integrity of the floe. Significant movement occurred at all buoy sites (Figure 6f).

26 The SI04-KP03 baseline length decreased from $179.3 \mathrm{~m}$ to $84.8 \mathrm{~m}(\Delta \mathrm{L}=-94.5 \mathrm{~m})$,

27 SI04-KP04 decreased from $248.7 \mathrm{~m}$ to $106.7 \mathrm{~m}(\Delta \mathrm{L}=-142.0 \mathrm{~m})$, and SI04-KP08

28 decreased from $169.7 \mathrm{~m}$ to $67.3 \mathrm{~m}(\Delta \mathrm{L}=-102.4 \mathrm{~m})$, all well above the baseline

29 length error $\sigma_{\mathrm{L}}$ (Table 2). To put these changes in context, to their initial baseline

30 lengths, these changes in $\Delta \mathrm{L}$ represent a reduction in baseline distances by at least

$3150 \%$ (Table 2). This indicates the immense compressive forcing that occurred

32 during this dramatic event, which resulted in substantial mechanical redistribution

33 of relatively thicker sea ice through the process of ridge building. 
From Figure 6c we can clearly see that KP03, KP04 and KP08 were all pushed more than $100 \mathrm{~m}$ towards SI04. It should be noted that because we discuss motions

3 relative to SI04 from a purely kinematic viewpoint, there is an inherent ambiguity

4 about which moved relative to which. Either way, there is no ambiguity about the

5 compressive nature of the event.

These movements transformed the shape of the array from a long, very narrow triangle to a short, almost equilateral triangle (Figure 6c). This corresponds

8 to shrinking of the outermost buoy array (Area A) of almost $2100 \mathrm{~m}^{2}$ compared to

9 the array area on deployment $\left(4797 \mathrm{~m}^{2}\right)$, almost $44 \%$ reduction of the area (Table

103 ). If we assume that ice was on average $1 \mathrm{~m}$ thick then this event redistributed

11 approximately 2 million kilograms of ice within the region bounded by the buoys.

12 (Note this area change $\Delta \mathrm{A}$ is well over the area error limit $\sigma_{\mathrm{A}}$ ).

13 Again, the differential nature of deformation can be seen through the very 14 different movements of the buoys on the floe. KP08 and KP03 that were very close 15 together $(7.4 \mathrm{~m})$ after the previous D16 event moved significantly apart (68.1 m) 16 during the D21 event (Figure 6f).

\section{5. Discussion}

\section{$18 \quad$ 5.1. Freeze-up at local and basin scale}

19 The dynamics of the sea ice is balanced between the inertia, air and water stress on

20 its upper and lower surfaces, the Coriolis force, sea-surface tilt, and internal ice

21 stress gradient (e.g., Hunkins, 1975; Steele et al., 1997). These spatially and

22 temporally varying forces influence internal ice stress that causes deformation

23 within ice field. The internal ice stress on a free drifting floe in summer (a time of

24 low compactness) is very different from that of a floe constrained by winter pack

25 ice. If we are to better understand the nature of some of the above mentioned forces

26 and associated deformation, it is important to understand how the consolidation of

27 ice proceeded (i.e., freeze-up) both at local spatial scales near the buoy location as

28 well as at large basin scales (covering pan-Arctic).

29 5.1.1. Local freeze-up

30 The buoys were deployed in late summer when the ice pack is particularly open, so

31 the drift of our instrumented floe more resembles a 'free drift' scenario. Local 
1 freeze-up at the buoy location marks the transition of ice conditions from a loosely

2 dispersed assortment of ice floes to a near-continuous ice sheet in the surrounding

3 area. A time-series of high-resolution TerraSAR-X (TSX) Synthetic Aperture Radar

4 (SAR) images acquired in the region near the floe location from late August 2012 to

5 late October 2012 clearly visualize this transition (Figure 7a to 7c). On 29 August

6 2012, the TSX SAR image shows that individual ice floes (brighter tone) are not

7 consolidated together and open water (much darker tone) exists in between floes

8 (Figure 7a). TSX SAR image on 2 October 2012 shows the formation of new ice

9 between the existing multiyear ice floes (new ice can be identified as darker tone

10 surrounding brighter toned multiyear ice floes) (Figure 7b). The high backscatter in

11 some regions of the image indicates the possible formation of frost flowers over the

12 young active growing ice (Isleifson et al., 2010). The 25 October 2012 TSX SAR

13 image shows much more consolidated ice condition with almost no open-water area

14 in the region (Figure 7c).

15 This ice formation and consolidation scenario seen by the SAR imagery

16 reasonably agrees with environmental and dynamical information provided by the

17 buoys on the floe. In the month preceding October 15, the air temperature

18 remained above $-10{ }^{\circ} \mathrm{C}$ and the drift speed of the floe was $0.20 \mathrm{~m} \mathrm{~s}^{-1}$ on average. In

19 the month after October 15, however, the air temperature began to drop below -10

$20{ }^{\circ} \mathrm{C}$ and ice drift speed decreased to $0.17 \mathrm{~m} \mathrm{~s}^{-1}$, a decrease of $0.03 \mathrm{~m} \mathrm{~s}^{-1}$. Although

21 dropping in air temperature after October 15 qualitatively confirms the timing of

22 local freeze-up, determining the freeze-up based on changes in ice drift speed is not

23 robust as the standard deviation of ice drift speed is quite high at $0.1 \mathrm{~m} \mathrm{~s}^{-1}$.

24 A more sound determination of local freeze-up can be found from the floe

25 rotation (change in baseline orientation $\Delta \theta$ ), because the rotation of a floe in free

26 drift would be higher than in a floe in the region of consolidated pack. We estimated

27 the variation of the floe rotation using the techniques developed by Mardia (1972).

28 It measures the dispersion of a directional dataset $r$, where $r=1$ implies all data is

29 coincident and $r=0$ implies uniform dispersion (i.e., smaller $r$ means larger variance

30 in direction). Using this method, we found the dispersion $r$ was significantly lower

31 before freeze up ( $\mathrm{r}=0.73)$ than after freeze up $(\mathrm{r}=0.99)$. Given this fact and

32 combined with the TSX SAR analysis, it is very likely that the sea began to freeze

33 early to mid-October near the buoy location, and was well advanced by the end of

34 October. 
2 In the above section we described local-scale freeze-up as the timing when sea ice

3 near the floe location became consolidated together. During this period (mid-

4 October) sea ice edge did not extend into the coastal line in the Pacific Sector of the

5 Arctic, yet there were still significant open water areas existing between the ice edge

6 and the coastal line (not shown here). Considering that compressive sea ice

7 strength can be built up as winds pushed the ice against or along the coastal line

8 (Tremblay and Hakakian, 2006), the timing when sea ice cover is consolidated to the

9 coastal line is an important factor. Pan-Arctic SIC maps show that the basin-scale

10 freeze-up occurred about two weeks prior to the deformation events, roughly

11 between late November and early December 2012.

12 The internal ice stress $\sigma_{\mathrm{i}}$ is proportional to wind stress $\tau_{\mathrm{a}}$ and fetch $\mathrm{L}_{\mathrm{f}}$, i.e., $\sigma_{\mathrm{i}}$

$13 \sim \tau_{\mathrm{a}} \times \mathrm{Lf}_{\mathrm{f}}$ (Tremblay and Hakakian, 2006). Thus, the effects on basin-scale freeze-up

14 on internal ice stress (and resulting deformation) are discussed in these two factors.

15 For the effects of wind stress, we first look at the mean sea level pressure (SLP)

16 pattern during December 2012. The pressure pattern shows the characteristics of

17 strong negative phase of the Arctic Oscillation (AO) (Figure 8a), i.e., higher SLP in

18 the high Arctic. Associated with this mean SLP pattern, the ice motion in the

19 Beaufort Sea and Chukchi Sea was mainly southward toward the coast. In contrast

20 to the mean SLP pattern, during the three deformation events the pressure pattern

21 exhibited the occurrence of low-pressure systems (Figure 8b-d), and the associated

22 ice motion was also quite different as well (Figure 9a-c). During both D13 and D16

23 events, the pattern is characterized by a strong low-pressure system in the East

24 Siberian Sea (associated with strong cyclonic ice motion). During the D21 event the

25 centre of the low-pressure system was shifted more toward inland of the East

26 Siberia than the other two cases.

$27 \quad$ At the floe location (marked as a red circle in Figure 9), all the three cases are 28 characterized by northward ice motion, accompanied with the passage of a low-

29 pressure system. The passage of a low-pressure system will influence the local

30 characteristic of ice drift in the region and, in turn, will produce variability within

31 internal pressure field that is dependent on the spatial distribution of ice properties

32 in that particular drift direction. This is the most obvious during D21 in which large-

33 scale ice motion shows strong northward ice motion all the way from the Alaskan

34 coast to the floe, whilst north of the floe the ice motion becomes weaker (Figure 9c). 
1 This suggests that the presence of sea ice pack to the north is inhibiting the

2 northward ice motion. Another factor to consider is the length of fetch $\mathrm{L}_{f}$ over which

3 wind stress is applied across the surface of the sea ice cover. Once sea ice forms

4 continuously across the basin, it would increase effective $\mathrm{L}_{\mathrm{f}}$ significantly. Recall the

5 deformation events occurred about two month after local freeze-up, and about two

6 weeks after the basin-scale freeze-up. This would allow sufficient time for sea ice to

7 grow thicker and mechanically rigid, forming a continuous ice field around the floe,

8 like a mechanical continuum.

9 The results indicate that both large-scale wind pattern (ice motion) and

10 basin-scale ice freeze-up would have impacts on the internal ice stress, and thus the

11 small-scale deformation events. It should be noted that this is mainly based on a

12 limited number of cases and also based on qualitative evaluation. More quantitative

13 and robust relationship between large scale winds and internal ice stress

14 (deformation) requires further investigation. For example, including new

15 parameters such as horizontal gradient of ice motion, ice thickness, and ice

16 temperature distribution should be considered, rather than simply correlating

17 basin-scale mean wind stress with deformation.

\section{$18 \quad$ 5.2. Strain rate}

19 Schulson (2004) estimated that the ductile-to-brittle transition strain rate was as

20 low as the order of $10^{-8} \mathrm{~s}^{-1}$. This relatively low transitional value was attributed to

21 larger stress concentrators normally found in sea ice (e.g., cracks, leads, and

22 refrozen melt ponds at the length scale of $100 \mathrm{~m}$ ). Our case also resembles ice

23 condition that is highly heterogeneous (horizontal thickness variation), composed of

24 stress concentrators such as refrozen melt ponds and cracks created by the ship

25 track (Figure 1d).

26 To estimate strain rate, we used the pairs of buoys, as opposed to use

27 multiple buoys to calculate full sets of deformation (see Hutchings and Hibler,

28 2008). The reasons are:

29 a) by using multiple buoys, GPS errors from the IMBs $(\sim 5 \mathrm{~m})$ get further

30 amplified and become too large to estimate deformation over a small array

$31 \quad\left(<3 \mathrm{~km}^{2}\right)$ (Hutchings et al. 2012), and

32 b) GPS sampling times between IMBs were not synchronized, which can also

33 contribute to increasing the error due to the time difference. By focusing on 
the sets of IMBs paired with the geodetic-quality (cm accuracy) GPS buoy (SI04), we can minimize the propagation of GPS errors in calculation of deformation rate.

We thus calculated one-dimensional (natural) strain rate $\varepsilon_{\mathrm{L}}$ along the baseline length $\mathrm{L}$ defined as

$$
\varepsilon_{L}=V_{L}(t) / L(t)
$$

$$
\text { where } V_{L}=[d L(t+d t)-L(t)] / d t \text {. }
$$

Here $\mathrm{V}_{\mathrm{L}}$ is the rate of change of the baseline length $\Delta \mathrm{L}$ at time $\mathrm{t}$. This is similar to that which was used in Rampal et al. (2008) who estimated the dispersion of pairs of drifters, although we use natural strain as opposed to Lagrangian strain (i.e., measure change in baseline length relative to the initial baseline length). Note that being one dimensional strain rate, $\varepsilon_{\mathrm{L}}$ cannot distinguish between divergence and convergence from shear. For large deformations ( $>15 \%$, as in our case), the natural strain is more appropriate.

More explicit deformation rate can be calculated for each pairs of buoys in a two-dimensional space having SI04 as the reference of the coordinate system. Assuming that velocity is constant within the time scale, the two invariants of the deformation, the divergence $\varepsilon_{\mathrm{d}}$ and shear strain $\varepsilon_{\mathrm{s}}$, can be calculated from velocity vectors as:

$$
\varepsilon_{d}=u_{x}+v_{y} \text { and } \varepsilon_{s}=\left[\left(u_{x}-v_{y}\right)^{2}+\left(u_{y}+v_{x}\right)^{2}\right]^{1 / 2}
$$

The magnitude of the total deformation $\varepsilon_{\mathrm{t}}$ can be obtained by:

$$
\varepsilon_{t}=\left[\varepsilon_{d}^{2}+\varepsilon_{s}^{2}\right]^{1 / 2}
$$

Figure 10 shows the temporal variability of the calculated deformation rates $\left(\varepsilon_{\mathrm{L}}\right.$ (black), $\varepsilon_{\mathrm{d}}$ (blue), $\varepsilon_{\mathrm{s}}$ (green), $\varepsilon_{\mathrm{t}}$ (red)) for the two pairs of buoys, SI04-KP03 and SI04-KP08, spanning the deformation events. Deformation rates were calculated at the time scale of $12 \mathrm{~h}$, which was the maximum GPS sampling rate set by both KP03 and KP08 during this period (Table 1). We did not use KP04 for the strain rate calculation as it shows much larger GPS errors than KP03 and KP08. Total strain rate calculated from SI04-KP04 at the 12-h time scale shows the magnitude similar to the ones from SI04-KP03 (not shown here). 
Hutchings et al. (2012) presents an error analysis in calculation of strain rate

2 for multiple buoys (see Eq. A4 in their paper). We adapted their error estimation

3 into our case, in which the strain error $\left(\sigma_{\varepsilon}\right)$ can be estimated as:

$4 \quad \sigma_{\varepsilon}=\sqrt{2} \sigma_{g p s} / T L$

5 where GPS error $\left(\sigma_{\varepsilon}=5 \mathrm{~m}\right)$, GPS sampling rate $(\mathrm{T})$ and baseline length $(\mathrm{L}=100 \mathrm{~m})$.

6 The estimated strain rate errors are $1.9 \times 10^{-5}, 3.2 \times 10^{-6}$, and $1.6 \times 10^{-6} \mathrm{~s}^{-1}$ for $\mathrm{T}=1,6$,

7 and $12 \mathrm{~h}$, respectively. These are shown in Figure 10 as horizontal, grey dash-dot

8 lines. As can be seen in the Figure, strain rate errors are larger than the deformation

9 signal, except for the D21 event, at the 1-h GPS sampling rate, but strain rate errors

10 become sufficiently small when we compared to our observations for GPS sampling

11 rates of 6 hours and slower.

12 Strain rate $\varepsilon_{\mathrm{L}}$ estimated from baseline length is consistently lower than total

13 deformation rate $\varepsilon_{\mathrm{t}}$ by a factor of 4 . Similar relation between strain from dispersion

14 and total deformation rate was observed in Rampal et al. (2008). The three events

15 are clearly distinctive by peaks in total deformation $\varepsilon_{t}$, which is within the range of

16 the order of $10^{-5} \mathrm{~s}^{-1}$ at the 12 -h time scale (Figure 10). This value is larger than the

17 transitional value $\left(10^{-8} \mathrm{~s}^{-1}\right)$ estimated by Schulson (2004), but is smaller than the

18 value $\left(10^{-4} \mathrm{~s}^{-1}\right)$ used in Marsan et al. (2004).

19 A wide range of ductile-to-brittle transitional strain rates (ranging from 10-8

$20 \mathrm{~s}^{-1}$ to $10^{-4} \mathrm{~s}^{-1}$ ) has been reported in the literature (Schulson, 2001 and 2004; Sodhi,

21 2001). The main reason for the existence of such a wide range of the transitional

22 values is due to different length scale for the stress concentrators (i.e., cracks/leads)

23 at different spatial scales. The original model equation to estimate the ductile-to-

24 brittle transitional strain rate was based on micro-scale laboratory experiments, and

25 then the transitional value for the large-scale sea ice fracture was estimated from

26 the same model and parameters across the scale except the length scale of stress

27 concentrator d, like cracks/leads in sea ice. Figure 11 illustrates how the brittle

28 transitional strain rate estimates vary with the length scale of stress concentrators.

29 It is interesting to note that the transitional strain rate is of order of $10^{-8} \mathrm{~s}^{-1}$ for the

30 range of the length of $200 \mathrm{~m}(\mathrm{~d}=200 \mathrm{~m})$, but quickly increases when the length

31 scale become smaller than $100 \mathrm{~m}$. This demonstrates that statistics of cracks/leads

32 is important to understand the brittle failure of sea ice. In our experiment, the range 
1 of brittle fracture strain rates that we observed matches with the model estimation

2 by Schulson (2001) for the length of stress concentrators of about $5 \mathrm{~m}(\mathrm{~d} \approx 5 \mathrm{~m})$.

Marsan et al. (2004) applied multi-scaling extrapolation to meter scale, and

4 estimated about $15 \%$ of the deformation is larger than $10^{-4} \mathrm{~s}^{-1}$ at the 3-day time

5 scale, implying over $0.2 \%$ of the total area. On the other hand Kwok (2001)

6 estimated the brittle failure strain rate of $10^{-7} \mathrm{~s}^{-1}$, for the same time scale, accounts

7 for $1 \%$ of total deformation of a day. As we discussed above, the brittle strain rate is

8 highly dependent on spatial scale, and thus those estimates of how much brittle

9 failure would occur needs to be examined with caution.

10 For the temporal scale, the studies mentioned above used satellite derived

11 data (i.e., products from the Radarsat Geophysical Processor System, or RGPS), and

12 have 3-day time steps. It is important to note that our deformation events would

13 remain undetected at 3-day time scales. To examine this, we lowered the time scale

14 from 12 hours to 2 days and calculated total strain rate $\varepsilon_{t}$ accordingly. The results

15 for the time scale of 2 days (black line), 1 day (green line), and 12-h (red line) are

16 shown in Figure 10c. The strain rate for 1-day time scale clearly fails to detect the

17 D13 and D16 deformation events, and for the D21 event it is still above the strain

18 error but reduced by half compared to the 12-h sampling (Figure 10c). For the 2-day

19 time scale, the strain rate become too small and none of the deformation events

20 could be detected. This suggests that the satellite data with the 3-day time scale

21 would significantly underestimate the amount of intermittent, small-scale brittle

22 failure of total deformation.

\section{5.3. Atmospheric forcing}

24 To examine the effects of atmospheric forcing we used surface 10-m wind data from

25 ERA Interim reanalysis of the European Centre for Medium-Range Weather

26 Forecasts (ECMWF), obtained from the British Atmospheric Data Centre (BADC). We

27 first extracted the 6-hr surface wind data that was nearest to the GPS location of the

28 floe at each time step (maximum distance between the GPS location and nearest grid

29 point was less than $40 \mathrm{~km}$ ), and then calculated the magnitude of wind components

30 (wind speed) for November and December months which is shown in Figure 6d. The

31 figure shows that the strong wind (above $10 \mathrm{~m} / \mathrm{s}$ ) occurred during each

32 deformation event, but even stronger wind events also occurred in mid-November

33 (although the start of local freeze-up commenced about a month earlier). Then one 
1 can ask a question why we did not see the deformation at our instrumented ice floe

2 during other strong wind events. To answer this question we examine the force

3 balance of the particular ice floe on which the buoys were deployed.

It has been shown that the force balance of sea ice in the Arctic Ocean away

5 from the coastal areas and in autumn and winter can be described by three

6 components; wind stress $F_{a}$, water drag $F_{w}$, and internal ice stress gradient $F_{i}$ as

$7 \quad F_{a}+F_{w}+F_{i}=0$ (e.g., Hunkins, 1975; Steele et al., 1997). As water drag $F_{w}$ and internal

8 stress gradient $F_{i}$ are both directed to the opposite to the ice velocity vector, they act

9 like damping to the magnitude of ice velocity vector (ice speed, $\mathrm{U}$ ) without altering

10 the direction of the vector (Steele et al., 1997). This is the main reason why ice

11 speed is highly correlated with wind speed $U_{a}$, although three forces are balanced. At

12 the time scale longer than a day, the three-force balance is a reasonable assumption

13 (Steele et al., 1997), but at smaller scale (shorter than a day) acceleration (inertia)

14 cannot be ignored (e.g., Weiss, 2013). As we are investigating small-scale

15 deformation in this study, the force balance can be expressed by four force terms as

$16 \quad F_{a}=F_{w}+F_{i}+A$, where $A$ is acceleration. (Note that $F_{w}$ and $F_{i}$ are always negative but $A$

17 is positive or negative depending on the acceleration.) To estimate relative

18 magnitude between forces we first decompose the observed ice speed $U$ into mean

19 ice speed $U_{m}$ and a speed perturbation $U^{\prime}$, as follows, $U=U_{m}+U^{\prime}$.

20 Here we view $U$ as ice speed forced by $F_{a}$, but damped down by both $F_{w}$ and $F_{i}$, and

21 also accelerated (or decelerated) at A. This can be written as:

$22 \quad U=U_{a}+U_{w}+U_{i}+U_{A}$,

23 where $U_{a}$ is the ice speed forced by $F_{a}, U_{w}$ is the ice speed damped by $F_{w}, U_{i}$ is the ice

24 speed damped by $\mathrm{F}_{\mathrm{i}}$, and $\mathrm{U}_{\mathrm{A}}$ is ice speed accelerated at $\mathrm{A}$. Furthermore each

25 components of $U$ can be also decomposed as follows;

$\mathrm{U}_{\mathrm{a}}=\mathrm{U}_{\mathrm{a}}^{\mathrm{m}}+\mathrm{U}_{\mathrm{a}}{ }^{\prime} ; \mathrm{U}_{\mathrm{w}}=\mathrm{U}_{\mathrm{w}} \mathrm{m}+\mathrm{U}_{\mathrm{w}}{ }^{\prime} ; \mathrm{U}_{\mathrm{i}}=\mathrm{U}_{\mathrm{i}}^{\mathrm{m}}+\mathrm{U}_{\mathrm{i}}^{\prime} ;$ and $\mathrm{U}_{\mathrm{A}}=\mathrm{U}_{\mathrm{A}}^{\mathrm{m}}+\mathrm{U}_{\mathrm{A}^{\prime}}$.

$27 \quad \mathrm{U}_{\mathrm{m}}$ represents the mean state, and this can be estimated from the constant ratio

$28\left(\mathrm{U} / \mathrm{U}_{\mathrm{a}}\right)$ if one assumes ocean current is negligible. It should be noted that $\mathrm{U}_{\mathrm{m}}$

29 technically includes mean state of combined contributions of $F_{a}, F_{w}, F_{i}$ and A, i.e., $U_{m}$

$30=U_{\mathrm{a}}{ }^{\mathrm{m}}+\mathrm{U}_{\mathrm{w}}{ }^{\mathrm{m}}+\mathrm{U}_{\mathrm{i}}{ }^{\mathrm{m}}+\mathrm{U}_{\mathrm{A}}{ }^{\mathrm{m}}$. On the other hand, $\mathrm{U}^{\prime}$ represents perturbation of combined

31 contributions of of $F_{a}, F_{w}, F_{i}$, and A, i.e., $U^{\prime}=U_{a}{ }^{\prime}+U_{w}{ }^{\prime}+U_{i}{ }^{\prime}+U_{A^{\prime}}$.

32 We first calculated $U_{m}$ by averaging the ratio $\left(U / U_{a}\right)$ over 6 hour for the

33 months of November and December 2012, obtaining $U_{m}=0.018 \mathrm{~m} \mathrm{~s}^{-1} \pm 0.007$ 
$1 \quad(\mathrm{~N}=244)$. This value is comparable to or slightly larger than the values reported in 2 some of previous studies (Shu et al., 2012; Fissel and Tang, 1991; Thorndike and 3 Colony, 1982), although other studies have shown smaller values (Lukovich et al., 4 2011). $U^{\prime}$ was then calculated by $U^{\prime}=U-U_{m}$. Figure 5e shows the perturbation of 5 ice speeds in the form of kinetic energy (i.e., $\mathrm{U}^{\prime}$ multiplied by $\mathrm{F}_{\mathrm{a}}$ ). First note that 6 there are positive peaks in $\mathrm{F}_{\mathrm{a}} \times \mathrm{U}^{\prime}$ (red line). If $\mathrm{U}_{\mathrm{m}}$ reasonably represents mean state, 7 the positive $F_{a} \times U^{\prime}$ indicates relative contribution of excessive acceleration $\left(U_{A^{\prime}}\right)$. For 8 example the very large positive $F_{a} \times U^{\prime}$ during November 9-15 is clearly associated 9 with the oscillatory pattern in which ice floe accelerates upon increased $\mathrm{F}_{\mathrm{a}}$ and 10 decelerates through relaxation as $\mathrm{F}_{\mathrm{a}}$ decreases. It is important to note that $\mathrm{F}_{\mathrm{a}} \times \mathrm{U}^{\prime}$ 11 converges to zero in the absence of $U_{A^{\prime}}$. In other occasions $F_{a} \times U^{\prime}$ is negative. Note 12 that such negative $U^{\prime}$ values can be due to further damping by excessive $F_{w}$ and $F_{i}$

13 (i.e., $U_{w}{ }^{\prime}$ and $\left.U_{i}{ }^{\prime}\right)$. If we define the excessive damping as $U_{d}{ }^{\prime}\left(U_{d}{ }^{\prime}=U_{w}{ }^{\prime}+U_{i}{ }^{\prime}\right)$, the

14 variation of $\mathrm{F}_{\mathrm{a}} \times \mathrm{U}^{\prime}$ can be interpreted as perturbation of relative magnitude between $15 \mathrm{U}_{\mathrm{d}}{ }^{\prime}$ (negative) and $\mathrm{U}_{\mathrm{A}^{\prime}}$ (positive).

Keeping in mind $\mathrm{U}_{\mathrm{d}}{ }^{\prime}$ is negative and $\mathrm{U}_{\mathrm{A}^{\prime}}$ is positive, the variation of $\mathrm{F}_{\mathrm{a}} \times \mathrm{U}^{\prime}$ reveals interesting kinetic energy balance. We can see that before December 9 the peaks of high $\mathrm{F}_{\mathrm{a}}$ (high wind events) are associated with the positive $\mathrm{F}_{\mathrm{a}} \times \mathrm{U}^{\prime}$, meaning the energy gained by $F_{a}$ is dissipated through excessive acceleration $\left(U_{A^{\prime}}\right)$ at the floe scale, or by the deformation within thin new ice area at the large scale. As mentioned above very large peaks of $\mathrm{F}_{\mathrm{a}} \times \mathrm{U}^{\prime}$ (red line) occurred during November 9-

2215 (Figure $5 \mathrm{a}$ and $5 \mathrm{e}$ ). These large peaks clearly indicate significant excessive 23 acceleration of the floe (which can also confirm the potential presence of 24 deformation of ice at the large scale). Particularly note that after the peak on 13

25 November 2012, $\mathrm{F}_{\mathrm{a}} \times \mathrm{U}^{\prime}$ decreases as it fluctuates at 12 -hr cycle. This clearly indicates 26 the effects of inertial motion of the ice floe. Recall local freeze-up began from mid27 October 2012 (Section 5.1), so this occurred almost one month after the local freeze28 up commenced. Once new ice rigidly forms around the floes (like seen in the TSX 29 SAR images in Figure $7 \mathrm{~b}$ and $7 \mathrm{c}$ ), the ice acts like a mechanical continuum, inertial 30 motion of ice pack is significantly reduced. In our case the inertial motion damped 31 down within about 2 days. This is close to the decay scale estimated from mooring 32 data when ice cover was more than 90\% (Martini et al., 2014). A plausible explanation is that new ice surrounded the floe was thinner and 34 more breakable than thicker MYI floes, and under strong wind stress this new ice 
1 was deformed and fractured. As the energy is dissipated through deformation over

2 the new ice, the amount of energy transferred to the ice floe would be significantly

3 reduced, so no deformation observed at the floe. Instead it causes the ice floe to be

4 broken loose from the surrounding ice and perform near-free drift. Once winds

5 subsided, the free drifting ice floe exhibited inertial ice motion in broken ice

6 condition. Another plausible explanation is that the whole ice cover moved in

7 inertial motion. This significantly reduces the energy transfer from wind forcing to

8 the mixed layer (Martini et al., 2014), so no deformation of the floe was observed.

9 The positive $F_{a} \times U^{\prime}\left(U_{A}^{\prime}\right)$ decreases as we approach December 11, while the

10 negative $F_{a} \times U^{\prime}$ appear on December 11,14 , and 17 , meaning excessive damping

$11\left(U_{d^{\prime}}\right)$ began to play a more significant role. This transition coincides with very sharp

12 decrease in air temperature, to below $-30{ }^{\circ} \mathrm{C}$ (Figure $5 b$ ). The negative $\mathrm{F}_{\mathrm{a}} \times \mathrm{U}^{\prime}$ on

13 December 11 may indicate, in conjunction with the cold temperatures, the

14 thickening of new ice surrounded with the floe. This more compact and thicker ice

15 means the increases in $\mathrm{F}_{\mathrm{i}}$ through ice. However, the immediate effects of more

16 compact and thicker ice on $\mathrm{F}_{\mathrm{w}}$ are not straightforward. This is because the ice-ocean

17 drag coefficient changes over time, i.e., deformation influences the ice bottom

18 geometry and thus affects $\mathrm{F}_{\mathrm{w}}$ (Lu et al., 2011). During the D13 deformation event

$19 \mathrm{~F}_{\mathrm{a}} \times \mathrm{U}^{\prime}$ is slightly negative, and deeper negative peaks occur during the D16 event,

20 indicating sudden damping in ice speed (i.e., increase in excessive $\mathrm{U}_{\mathrm{d}}{ }^{\prime}$ ) (Figure $5 \mathrm{e}$ ).

21 We cannot confidently say how much these negative peaks were associated with

22 increase between $F_{w}$ and $F_{i}$.

23 On the other hand, the D21 event is characterized by positive peaks of $\mathrm{F}_{\mathrm{a}} \times \mathrm{U}^{\prime}$.

24 This may suggest that the D21 event differs from the D13/16 events in terms of

25 dynamic characteristics, i.e., $U_{A^{\prime}}$ vs $U_{d^{\prime}}$. During the D13/D16 events the drift speed

26 (and environment parameters) were rather stable, while very dramatic changes

27 were observed in ice drift speed (and environmental parameters) during the D21

28 event (see Section 4 and Figure 4). The wind vectors along the track also depict the

29 characteristics of two different dynamic regimes (Figure 12). During the D13/D16

30 events, the wind vectors were steady in magnitude and direction, but the wind

31 direction right before the D21 event changed rapidly twice for a total of almost $300^{\circ}$,

32 and then the wind speed increased throughout the event.

33 The large-scale SLP pattern during the D21 event is also different from those

34 during the two other events. During the D21 event the center of low-pressure 
1 system was located south in the East Siberia (Figure 8d). This caused very strong

2 northward ice motion from the coast of the Chukchi Sea through to the buoy

3 location, but the ice motion was reduced in the north of the floe location (Figure 9c).

4 This creates strong south-to-north gradient in ice motion, which significantly

5 increase internal ice stress in the buoy area. In Figure $5 \mathrm{e}$ this shows as increase in

6 excessive acceleration of the floe $\left(U_{A^{\prime}}\right)$ (positive red line), while the D13/D16 events

7 are seen as increase in damping $\left(U_{d^{\prime}}\right)$. We here emphasize that the estimation of the

8 force balance was made at the floe scale, so the results should be understood in the

9 context of both the floe scale as well as large scale. During the D13/D16 events the

10 ice floe was consolidated together with surrounding ice, i.e., a mechanical

11 continuum. Thus the negative $F_{a} \times U^{\prime}$ can be seen as the resistance to the applied $F_{a}$,

12 an increase of internal ice stress $F_{i}$ of the ice continuum. On the other hand, the

13 positive $\mathrm{F}_{\mathrm{a}} \times \mathrm{U}^{\prime}$ (excessive acceleration) during the $\mathrm{D} 21$ event seems the opposite to

14 what we expected. However, this can be seen as the effects of large-scale

15 deformation and brittle fracturing in the area, which causes cracks for the ice floe to

16 move more freely and accelerate.

17 Figure 13 contains the TSX SAR images acquired on 25 October 2012 and 23

18 December 2012. The October 25 image captured sea ice condition at the buoy

19 location before the deformation event (covering an area of 7 by $10 \mathrm{~km}$ ), yet the

20 December 23 image captured the ice condition right after the D21 deformation

21 event. Note that the December 23 failed to capture the exact floe location, but show

22 the area about $30 \mathrm{~km}$ north from the floe location. Here we attempt to see

23 immediate effects of the D21 deformation event. When the two images are

24 compared, the December 23 image clearly shows many fracture lines (thin brighter

25 lines in Figure 13b) which are not shown in the October 25 image (Figure 13a).

26 These lines are mainly shown within the dark-looking new ice area, but in some

27 cases the fracture lines appear across the MYI floe, indicating wide spread brittle

28 fracturing in the area.

\section{6. Summary and conclusions}

30 Small-scale ( $\sim 100$ to $200 \mathrm{~m}$ ) deformations of an Arctic ice floe were observed from

31 multiple GPS buoys deployed on the same ice floe. The types of buoys include a

32 geodetic-quality GPS system (SATICE, cm-level position error) and sea ice mass

33 balance buoys (IMBs) equipped with standard GPS (position error $\sim 5 \mathrm{~m}$ ). By 
1 pairing with a geodetic-quality SATICE-type buoy, the baseline length and

2 orientation of three IMBs (relative to SATICE) could be estimated with errors that

3 are sufficiently small ( $\sim 5 \mathrm{~m}$ in length and, depending on baseline length, 2 degrees

4 or less in orientation) enough to capture small-scale deformations.

$5 \quad$ No change in baseline length was detected for the three baselines from the

6 deployment in late August until mid-December 2012. And then both baseline length

7 and orientation changed abruptly during a series of three discrete deformation

8 events (D13, D16, and D21). Each deformation episode lasted less than a day. After

9 the deformation events the baseline length $L$ between the pairs of buoys shrank by

10 about $50 \%$, and the area covered by the buoy arrays decreased by 40 to $60 \%$ at the

11 end of the events, indicating violent compression of the floe (i.e., ridge building). Our

12 observations also showed complex and non-linear nature of the deformation as the

13 buoys separated by only $20 \mathrm{~m}$ moved differentially during the deformation.

14 Satellite imagery and dynamic parameters suggest that the local freeze-up

15 (consolidation of ice near the floe location) occurred at around mid-October, while

16 basin-scale freeze-up (consolidation of ice over the Pacific sector of the Arctic basin)

17 occurred at between late November and early December. Therefore, at the time of

18 deformation, it was already two months into ice growth near the floe location, and

19 about two weeks after basin-scale freeze-up. This allowed enough time for the new

20 ice between multiyear ice floes to be consolidated to form (mechanically)

21 continuous ice continuum. Basin-scale freeze-up also increased the length of ice

22 surface fetch affected by wind stress. In addition, sudden changes in ice motion

23 occurred during the three deformation events. During the deformation events low-

24 pressure systems dominated the SLP pattern which caused northward ice motion

25 toward the floe location and pushing ice against more stagnant pack ice in the north.

26 This is different from the December mean SLP pattern, showing high SLP in the high

27 Arctic. Combination of increased fetch and south-to-north gradient in ice motion

28 increases internal ice pressure and leads to favourable condition for the

29 deformation and brittle fracturing.

30 Strain rate estimated from the pairs of buoys was of the order of $10^{-5} \mathrm{~s}^{-1}$ at

31 the time scale of $12 \mathrm{~h}$. This range of strain rate is comparable to the ductile-to-brittle

32 strain rate estimate by Schulson (2001) for the length of crack of $5 \mathrm{~m}$. Actual strain

33 rate would be much larger as the actual deformation could occur much shorter than

$3412 \mathrm{~h}$. When the time scale lowers to 1 day, even the largest deformation event (D21) 
1 would be underestimated by $50 \%$ relative to our measurements. At the 2-day time

2 scale or longer our deformation events could not be detected.

3 Analysis of force balance reveals the relative effects between internal ice

4 stress gradient $F_{i}$ and acceleration $A$ under atmospheric wind stress. When new ice

5 formed between multiyear ice floes is still thin and weak, strong wind stress was

6 dissipated through deformation/fracturing over the new ice cover. This was shown

7 as (at the floe scale) an increase in acceleration (A, inertia) of the floe, indicating the

8 ice floe was broken loose from the surrounding new ice and move freely. As colder

9 condition $\left(<-30^{\circ} \mathrm{C}\right)$ prevailed, the thickness and strength of new ice between the

10 multiyear ice floes increased. Under strong wind stress the internal ice stress

11 gradient $F_{i}$ increased through ice cover. (These effects were shown as negative

12 peaks of $F_{a} \times U^{\prime}$ during the D13/D16 events.) This increases $F_{i}$ causing the

13 deformation/fracturing which we observed at the strain rate of about $2 \times 10^{-5} \mathrm{~s}^{-1}$ at

14 our floe location.

15 However, the most dramatic deformation event, D21, was shown as positive 16 peaks of $\mathrm{F}_{\mathrm{a}} \times \mathrm{U}^{\prime}$, i.e., acceleration of the ice floe. This can be seen as the effects of

17 large-scale deformation that causes fracturing of surrounding ice cover as well as at

18 the ice floe. This creates fracture cracks for the ice floe to move more freely and

19 accelerate. Low-pressure system during the D21 event was more shifted to the

20 down south in the East Siberia. This caused very strong northward ice motion to the

21 floe location, yet the ice motion in the north is much slower. This sharp south-to-

22 north gradient in ice motion is most evident during the D21 deformation in which

23 we observed most violent compression from our buoy data.

$24 \quad$ Wide-spread fracturing during these deformation events can be visualized in 25 satellite image (Terrsar-X ScanSAR) acquired on 23 December 2012 (just 18 hours

26 after the end of the D21 event). The December 23 image failed to capture the exact

27 floe location, but it still shows the sea ice conditions within $30 \mathrm{~km}$ from the floe

28 location. Comparing this image with the image acquired on 25 October 2012, it

29 shows many complex fracture cracks mainly in the dark-looking new ice area and

30 sometimes across the multiyear ice floes, indicating wide spread brittle fracturing in 31 the area.

32 In this study, qualitatively speaking, we see some effects of large-scale wind 33 stress (ice motion) on small-scale deformations. All three deformation events we

34 discussed in this study occurred when low-pressure systems were developed in the 
1 Arctic, a deviation from the December mean pressure pattern. The low pressure

2 systems caused northward ice motion toward the floe location and against stagnant

3 pack ice in the north. This causes very steep south-to-north gradient in ice motion,

4 causing significant build-up of internal ice stress and thus contributing to brittle

5 fracturing. This suggests the kinetic energy gained by wind stress can still be

6 associated with the small-scale deformation to some extent. At the same time, small-

7 scale deformation (at the floe scale) was not observed when surrounding newly

8 formed sea ice was still thin and fragile, as most of kinetic energy by wind stress

9 were effectively dissipated through deformation/fracturing within new ice cover.

10 This suggests that a simple correlation between wind stress and small-scale

11 deformation is difficult to be measured. Exploration of the relationship may require

12 new approach such as using wind stress gradient (not the mean magnitude), and

13 also require additional new parameters such as ice thickness and strength.

15 Acknowledgements

16 This work was partly supported by ACCESS, an European Project supported within

17 the Ocean of Tomorrow call of the European Commission Seventh Framework

18 Programme; SATICE, an European Science Foundation (ESF) PolarCLIMATE

19 Programme project; the Marginal Ice Zone (MIZ) Programme by the Office of Naval

20 Research (ONR); the Spanish Ministry of Science and Innovation (MICINN; now

21 MINECO); and the K-PORT (KOPRI, PM13020) project funded by the Ministry of

22 Oceans and Fisheries, South Korea. We acknowledge grateful support from KOPRI,

23 and the captain and crews of IBRV Araon during the ARA04B cruise. We also thank

24 engineers Markus Olsson of CSIC and Shane Rodwell, Alistair James, and Bernard

25 Hagan at SAMS for their involvement in SATICE instrument development and

26 deployment. The TerraSAR-X imagery in this project was acquired via DLR TSX SSS

27 project to BJH. ECMWF ERA Interim data were acquired from BADC. SIMB GPS data

28 is publicly available thanks to CRREL. We thank Jennifer Hutchings, and an

29 anonymous reviewer for constructive reviews.

30

$31 \quad$ References 
1 Elosegui, P., Davis, J.L., Oberlander, D., Baena, R., Ekström, G., 2006. Accuracy of highrate GPS for seismology, Geophysical Research Letters 33, L11308, doi:10.1029/2006GL026065.

Elosegui, P., J. Wilkinson, M. Olsson, S. Rodwell, A. James, B. Hagan, B. Hwang, R. Forsberg, R. Gerdes, J. Johannessen, P. Wadhams, M. Nettles, L. Padman, 2012. High-precision GPS autonomous platforms for sea ice dynamics and physical oceanography, Fall Meeting of the American Geophysical Union, C13E-0662, San Francisco.

Fissel, D.B., Tang, C.L., 1991. Response of sea ice drift to wind forcing on the northeastern Newfoundland Shelf. Journal of Geophysical Research 96 (C10), $18,397-18,409$.

Geiger, C.A., Zhao, Y., Liu A.K., Häkkinen, S., 2000. Large-scale comparison between buoy and SSM/I drift and deformation in the Eurasian Basin during winter 1992-1993. Journal of Geophysical Research 105 (C2), 3357-3368.

Herman, A., Glowacki, O., 2012. Variability of sea ice deformation rates in the Arctic and their relationship with basin-scale wind forcing, The Crysophere 6, 15531559.

Hutchings, J., Roberts, A., Geiger, C.A., Richter-Menge, J., 2011. Spatial and temporal characterization of sea-ice deformation. Annals of Glaciology 52 (57), 360368.

Hutchings, J.K., Heil, P., Steer, A., Hibler III, W.D., 2012. Subsynoptic scale spatial variability of sea ice deformation in the western Weddell Sea during early summer, J. Geophys. Res., 117, C01002, doi:10.1029/2011JC006961.

Hunkins, K., 1975. The oceanic boundary layer and stress beneath a drifting ice floe. Journal of Geophysical Research, 80(24), 3425-3433.

Isleifson, D., Hwang, B., Barber, D.G., Scharien, R.K., Shafai, L., 2010. C-Band Polarimetric Backscattering Signatures of Newly Formed Sea Ice During Fall Freeze-Up. IEEE Transactions on Geoscience and Remote Sensing 48 (8), 32563267.

Jackson, K., Wilkinson, J. Maksym, T., Beckers, J., Haas, C., Meldrum, D., Mackenzie, D., 2012. A Novel and Low Cost Sea Ice Mass Balance Buoy. Journal of Atmospheric and Oceanic Technology doi:10.1175/JTECH-D-13-0058.1. 
1 Kovacs, A., 1996. Sea ice: Part II, Estimating the full-scale tensile, flexural, and compressive strength of first-year ice. CRREL Rep. 96-11, Cold Reg. Res. and Eng Lab., Hanover, NH.

4 Kwok, R., Cunningham, G.F., 2012. Deformation of the Arctic Ocean ice cover after the 2007 record minimum in summer ice extent, Cold Regions and Technology, 76-77, 17-23.

Kwok, R., Rothrock, D.A., 2009. Decline in Arctic sea ice thickness from submarine and ICESat records: 1958 - 2008. Geophysical Research Letters 36, L15501,

Kwok, R., Sulsky, D., 2010. Arctic Ocean Sea Ice Thickness and Kinematics. Oceanography 23 (4), 134-143. doi:10.1029/2009GL039035.

Lu, P., Li, Z., Cheng, B., Leppäranta M., 2011. A parameterization of the ice-ocean drag coefficient, J. Geophys. Res., 116, C07019, doi:10.1029/2010JC006878.

Lukovich, J.V., Babb, D.G., Barber, D.G., 2011. On the scaling laws derived from ice beacon trajectories in the southern Beaufort Sea during the International Polar Year - Circumpolar Flaw Lead study, 2007-2008. Journal of Geophysical Research 116, C00G07, doi:10.1029/2011JC007049.

Mardia, K.V., 1972. Statistics of Directional Data. New York: Academic Press.

Marsan. D., Stern, H., Lindsay, R., Weiss J., 2004, Scale Dependence and Localization of the Deformation of Arctic Sea Ice. Physical Review Letters 93 (17), doi:10.1103/PhysRevLett.93.178501.

Parkinson, C.L., Comiso, J.C., 2013. On the 2012 record low Arctic sea ice cover: Combined impact of preconditioning and an August storm, Geophysical Research Letters 40, 1356-1361, doi:10.1002/grl.50349.

Petrich, C., Eicken, H., 2010. Growth, Structure and Properties of Sea Ice, In: Thomas D. N., Dieckmann, G. S. (Eds), Sea Ice. Second Edition, Wiley-Blackwell, Oxford, UK. doi:10.1002/9781444317145.ch2.

Polashenski, C., Perovich, D.K., Richter-Menge, J.A. Elder, B., 2011. Seasonal ice massbalance buoys: adapting tools to the changing Arctic. Annuals of Glaciology 52 (57), 18-26. 
1 Rampal, P., Weiss, J., Marsan, D., Lindsay, R., Stern, H., 2008. Scaling properties of sea ice deformation from buoy dispersion analysis. Journal Geophysical Research 113, C03002, doi:10.1029/2007JC004143.

Rampal, P., J. Weiss, J., Marsan, D., 2009. Positive trend in the mean speed and deformation rate of Arctic sea ice, 1979-2007. Journal of Geophysical Research 114, C05013, doi:10.1029/2008JC005066.

Richter-Menge, J.A., Elder, B.C., 1998. Characteristics of pack ice stress in the Alaskan Beaufort Sea. Journal of Geophysical Research 103 (C10), 21,817-21,829.

Richter-Menge, J.A., McNutt, S. L., Overland, J. E., Kwok, R., 2002. Relating arctic pack ice stress and deformation under winter conditions. Journal of Geophysical Research 107 (C10), 8040, doi:10.1029/2000JC000477.

Schulson, E.M., 2001. Brittle failure of ice. Engineering Fracture Mechanics, 68, 1839-1887.

Schulson, E.M., 2004. Compressive shear faults within arctic sea ice: Fracture on scales large and small. Journal of Geophysical Research 109, C07016, doi:10.1029/2003JC002108.

Shu, Q., Ma, H., Qiao, F., 2012. Observation and simulation of a floe drift near the North Pole. Ocean Dynamics 62, 1,195-1,200.

Simmonds, I., Rudeva, I., 2012. The great Arctic cyclone of August 2012. Geophysical Research Letters 39, L23709, doi:10.1029/2012GL054259.

Sodhi, D.S., 2001. Crushing failure during ice-structure interaction, Engineering Fracture Mechanics, 68, 1889-1921.

Steele, M., Zhang, J., Rothrock, D., Stern, H., 1997. The force balance of sea ice in a numerical model of the Arctic Ocean. Journal of Geophysical Research, 102 (C9), 21,061-21,079.

Thorndike, A.S., Colony, R., 1982. Sea ice motion in response to geostrophic winds. Journal of Geophysical Research 87 (C8), 5845-5852, doi:10.1029/JC087iC08p05845.

Tremblay, L.-B., Hakakian, M., 2006. Estimating the Sea Ice Compressive Strength from Satellite-Derived Sea Ice Drift and NCEP Reanalysis Data. Journal of Physical Oceanography 36, November, 2165-2172. 
1 Walter, B.A., Overland, J.E., 1993. The response of lead patterns in the Beaufort Sea

2 to storm-scale wind forcing. Annuals of Glaciology, 17, 219-226.

3 Weiss, J., 2013. Drift, Deformation, and Fracture of Sea Ice: A Perspective Across

4 Scales. Springer Briefs in Earth Sciences, doi: 10.1007/978-94-007-6202-2_2.

5 Zhang, J., Lindsay, R., Schweiger, A., Rigor, I., 2012. Recent changes in the dynamic

6 properties of declining Arctic sea ice: A model study. Geophysical Research

7 Letters 39, L20503, doi:10.1029/2012GL053545.

8 Zhang J., Lindsay, R., Schweiger, A., Steele, M., 2013. The impact of an intense

9 summer cyclone on 2012 Arctic sea ice retreat. Geophysical Research Letters

10 40, doi:10.1002/grl.5019.

11

12 
Table 1 Description of buoy deployment and measurements used in this study. $\mathrm{H}_{\text {snow }}$ and $\mathrm{H}_{\text {ice }}$ denote snow depth and ice thickness in metres respectively. Epoch is DD/MM/YY HH:MM in UTC. The buoy data actually used in the analysis are highlighted in bold in their ID names.

\begin{tabular}{|c|c|c|c|c|c|c|c|c|}
\hline $\begin{array}{l}\text { Buoy } \\
\text { Type }\end{array}$ & ID & $\begin{array}{l}\text { Deployme } \\
\text { nt Epoch }\end{array}$ & $\mathrm{H}_{\text {snow }}$ & $\mathrm{H}_{\text {ice }}$ & $\begin{array}{l}\text { Last GPS } \\
\text { reading }\end{array}$ & $\begin{array}{l}\text { Last chain } \\
\text { reading }\end{array}$ & GPS reading interval & Description \\
\hline \multirow{2}{*}{$\begin{array}{l}\text { High- } \\
\text { precisio } \\
\text { n GPS } \\
\text { (SATICE } \\
\text { ) }\end{array}$} & SI03 & $\begin{array}{c}13 / 08 / 12 \\
23: 00 \\
\end{array}$ & 0.07 & 1.20 & $\begin{array}{c}21 / 12 / 12 \\
17: 00 \\
\end{array}$ & N/A & $10 \mathrm{~s}$ & $\begin{array}{l}\text { Deployed on the level FYI about } 20 \mathrm{~m} \text { from the starboard side of the } \\
\text { ship. GPS readings available until } 21 \text { December } 2012 \text { (D21) event. }\end{array}$ \\
\hline & SI04 & $\begin{array}{l}14 / 08 / 12 \\
20: 00\end{array}$ & 0.09 & 1.06 & $31 / 06 / 13$ & N/A & $10 \mathrm{~s}$ & $\begin{array}{l}\text { Deployed on the level FYI about } 20 \mathrm{~m} \text { from the port side of the ship. } \\
\text { Used as the centre reference point for the baseline and array area } \\
\text { analysis. Air temperature, barometric pressure, and humidity } \\
\text { measured from this buoy also used in the analysis. }\end{array}$ \\
\hline \multirow{8}{*}{$\begin{array}{l}\text { Ice Mass } \\
\text { Balance } \\
\text { Buoys } \\
\text { (IMB) }\end{array}$} & КР01 & $\begin{array}{c}13 / 08 / 12 \\
23: 00 \\
\end{array}$ & 0.10 & 1.28 & $\begin{array}{c}14 / 09 / 13 \\
22: 00 \\
\end{array}$ & $\begin{array}{c}14 / 09 / 12 \\
23: 00 \\
\end{array}$ & 1 hour & $\begin{array}{l}\text { Deployed on the level FYI about } 6 \mathrm{~m} \text { from SI03. Prematurely failed and } \\
\text { excluded from the analysis. }\end{array}$ \\
\hline & КР02 & $\begin{array}{l}14 / 08 / 12 \\
20: 00\end{array}$ & 0.11 & 1.06 & $31 / 06 / 13$ & $\begin{array}{l}26 / 12 / 12 \\
17: 00\end{array}$ & $\begin{array}{l}-27 / 10: 1 \mathrm{~h} \\
27 / 10-30 / 10: 2 \mathrm{~h} \\
\text { 30/10-12/01: } 12 \mathrm{~h} \\
\text { 12/01-: } 1 \mathrm{~h}\end{array}$ & $\begin{array}{l}\text { Deployed on the level FYI about } 6 \mathrm{~m} \text { from SI04. Baseline distance } \\
\text { within the error range }(\sim 5 \mathrm{~m}) \text {, so not included in the analysis. }\end{array}$ \\
\hline & КР03 & $\begin{array}{l}15 / 08 / 12 \\
03: 00\end{array}$ & 0.14 & 3.17 & $31 / 06 / 13$ & $\begin{array}{l}21 / 12 / 12 \\
05: 00\end{array}$ & $\begin{array}{l}-05 / 10: 1 \mathrm{~h} \\
05 / 10-30 / 10: 2 \mathrm{~h} \\
\text { 30/10-12/01: } 12 \mathrm{~h} \\
\text { 12/01-: } 1 \mathrm{~h}\end{array}$ & $\begin{array}{l}\text { Deployed on the MYI about } 100 \mathrm{~m} \text { from the starboard side of the ship. } \\
\text { Used for both baseline and area analysis. }\end{array}$ \\
\hline & KP04 & $\begin{array}{l}\text { 15/08/12 } \\
03: 00\end{array}$ & - & 1.08 & $31 / 06 / 13$ & $\begin{array}{l}27 / 08 / 12 \\
12: 00\end{array}$ & $1 \mathrm{~h}$ & $\begin{array}{l}\text { Deployed on the MYI about } 150 \mathrm{~m} \text { from the ship's starboard side. Used } \\
\text { for both baseline and array analysis. }\end{array}$ \\
\hline & КР05 & $\begin{array}{l}15 / 08 / 12 \\
05: 00\end{array}$ & 0.05 & 3.00 & $\begin{array}{l}11 / 12 / 12 \\
16: 00\end{array}$ & $\begin{array}{l}21 / 12 / 12 \\
16: 00\end{array}$ & $\begin{array}{l}-05 / 10: 1 \mathrm{~h} \\
05 / 10-30 / 10: 2 \mathrm{~h} \\
30 / 10-: 12 \mathrm{~h}\end{array}$ & $\begin{array}{l}\text { Deployed on the MYI about } 150 \mathrm{~m} \text { from the ship's bow, GPS lost before } \\
\text { the deformation events, not included in the analysis. }\end{array}$ \\
\hline & КР06 & $\begin{array}{c}15 / 08 / 12 \\
05: 00\end{array}$ & 0.15 & 1.43 & $\begin{array}{l}23 / 08 / 12 \\
20: 00 \\
\end{array}$ & $\begin{array}{c}21 / 12 / 12 \\
15: 00 \\
\end{array}$ & $1 \mathrm{~h}$ & $\begin{array}{l}\text { Deployed on the same MYI with KP04. GPS lost before the deformation } \\
\text { events, not included in the analysis. }\end{array}$ \\
\hline & КР07 & $\begin{array}{l}14 / 08 / 12 \\
20: 00\end{array}$ & 0.12 & 1.01 & $\begin{array}{l}14 / 12 / 12 \\
19: 00\end{array}$ & $\begin{array}{l}21 / 12 / 12 \\
19: 00\end{array}$ & $\begin{array}{l}-05 / 10: 1 \mathrm{~h} \\
05 / 10-30 / 10: 2 \mathrm{~h} \\
30 / 10-: 12 \mathrm{~h}\end{array}$ & $\begin{array}{l}\text { Deployed on the smooth FYI about } 10 \mathrm{~m} \text { from SI04. GPS lost before the } \\
\text { deformation events, so used as supplementary data. }\end{array}$ \\
\hline & КP08 & $\begin{array}{l}13 / 08 / 12 \\
23: 00\end{array}$ & 0.09 & 1.07 & $\begin{array}{l}17 / 04 / 13 \\
15: 00\end{array}$ & $\begin{array}{l}21 / 12 / 12 \\
09: 00\end{array}$ & $\begin{array}{l}-05 / 10: 1 \mathrm{~h} \\
05 / 10-30 / 10: 2 \mathrm{~h} \\
\text { 30/10-12/01: } 12 \mathrm{~h} \\
\text { 12/01-: } 1 \mathrm{~h}\end{array}$ & $\begin{array}{l}\text { Deployed on the smooth FYI about } 20 \mathrm{~m} \text { from SI03. Used for both } \\
\text { baseline and array analysis. }\end{array}$ \\
\hline $\begin{array}{l}\text { Seasonal } \\
\text { Ice Mass } \\
\text { Balance } \\
\text { Buoy } \\
\text { (SIMB) } \\
\end{array}$ & $2010 \mathrm{I}$ & $\begin{array}{l}14 / 08 / 12 \\
03: 00\end{array}$ & 0.10 & 1.09 & $\begin{array}{l}21 / 12 / 12 \\
20: 00\end{array}$ & $\mathrm{~N} / \mathrm{A}$ & $1 \mathrm{~h}$ & $\begin{array}{l}\text { Deployed on the smooth FYI about } 5 \mathrm{~m} \text { from KP08. GPS readings } \\
\text { available until the Dec } 17 \text { event. }\end{array}$ \\
\hline
\end{tabular}


1 Table 2 Baseline length $\mathrm{L}$ and orientation $\theta$ of deformation events, relative to SI04.

$2 \Delta \mathrm{L}$ and $\Delta \theta$ are change in $\mathrm{L}$ and $\theta$, respectively, for the event, and $\Delta \mathrm{D}$ is the buoy

3 displacement. Distances are in meters $(\mathrm{m})$ and angles in degrees $\left({ }^{\circ}\right)$. Epoch format is

4 DD/MM/YY HH:MM, in UTC. $\sigma_{\mathrm{L}}$ and $\sigma_{\theta}$ are the error estimates for $\mathrm{L}$ and $\theta$,

5 respectively (see text for definition). SI04 and KP08 are in FYI, KP03 and KP04 in 6 MYI.

\begin{tabular}{|c|c|c|c|c|c|c|c|c|c|c|}
\hline \multirow[b]{2}{*}{$\begin{array}{l}\text { Baseline } \\
\text { (m) }\end{array}$} & \multirow[b]{2}{*}{ Epoch } & \multicolumn{3}{|c|}{ SI04 (FYI) - KP03 (MYI) } & \multicolumn{3}{|c|}{ S0I4 (FYI) - KP04 (MYI) } & \multicolumn{3}{|c|}{ SI04 (FYI) - KP08 (FYI) } \\
\hline & & $\begin{array}{c}\mathbf{L}(\mathbf{m}) \\
\sigma_{\mathrm{L}}\end{array}$ & $\begin{array}{c}\theta\left({ }^{\circ}\right) \\
\sigma_{\theta}\end{array}$ & $\begin{array}{c}\Delta \mathbf{L} \\
\Delta \mathrm{D} \\
\Delta \theta\end{array}$ & $\begin{array}{c}\mathbf{L}(\mathbf{m}) \\
\sigma_{\mathrm{L}}\end{array}$ & $\begin{array}{c}\theta\left({ }^{\circ}\right) \\
\sigma_{\theta}\end{array}$ & $\begin{array}{c}\Delta \mathrm{L} \\
\Delta \mathrm{D} \\
\Delta \theta\end{array}$ & $\begin{array}{c}\mathbf{L}(\mathbf{m}) \\
\sigma_{\mathrm{L}}\end{array}$ & $\begin{array}{c}\theta\left(^{\circ}\right) \\
\sigma_{\theta}\end{array}$ & $\begin{array}{c}\Delta \mathrm{L} \\
\Delta \mathrm{D} \\
\Delta \theta\end{array}$ \\
\hline $\begin{array}{c}\text { D13 } \\
\text { (Start) }\end{array}$ & $\begin{array}{c}13 / 12 / 12 \\
17: 00\end{array}$ & $\begin{array}{c}165.0 \\
4 \\
\end{array}$ & $\begin{array}{c}325.9 \\
1.4 \\
\end{array}$ & --- & $\begin{array}{c}211.8 \\
4 \\
\end{array}$ & $\begin{array}{c}327.2 \\
1.1 \\
\end{array}$ & --- & $\begin{array}{c}111.5 \\
4 \\
\end{array}$ & $\begin{array}{c}301.8 \\
2.1 \\
\end{array}$ & --- \\
\hline $\begin{array}{l}\text { D13 } \\
\text { (End) }\end{array}$ & $\begin{array}{c}14 / 12 / 12 \\
09: 00\end{array}$ & $\begin{array}{c}168.3 \\
4\end{array}$ & $\begin{array}{c}306.1 \\
1.4\end{array}$ & $\begin{array}{c}3.3 \\
57.4 \\
-19.8 \\
\end{array}$ & $\begin{array}{c}234.6 \\
4\end{array}$ & $\begin{array}{c}309.4 \\
1.0\end{array}$ & $\begin{array}{r}22.8 \\
72.6 \\
-17.8 \\
\end{array}$ & $\begin{array}{c}165.7 \\
4\end{array}$ & $\begin{array}{c}298.8 \\
1.4 \\
\end{array}$ & $\begin{array}{r}54.2 \\
54.7 \\
-3.0\end{array}$ \\
\hline
\end{tabular}

\begin{tabular}{|c|c|c|c|c|c|c|c|c|c|c|}
\hline $\begin{array}{c}\text { D16 } \\
\text { (Start) }\end{array}$ & $\begin{array}{c}16 / 12 / 12 \\
20: 00\end{array}$ & $\begin{array}{c}168.4 \\
4\end{array}$ & $\begin{array}{c}304.6 \\
1.4\end{array}$ & --- & 237.7 & 309.2 & -- & 164.5 & 295.1 & -- \\
\hline D16 & $17 / 12 / 12$ & 180.0 & 319.6 & 11.6 & 246.1 & 324.1 & 8.4 & 175.1 & 317.8 & 10.6 \\
(End) & $09: 00$ & 4 & 1.3 & 15 & 4 & 1.0 & 14.9 & 4 & 1.3 & 57.0 \\
\hline
\end{tabular}

\begin{tabular}{|c|c|c|c|c|c|c|c|c|c|c|}
\hline $\begin{array}{c}\text { D21 } \\
\text { (Start) }\end{array}$ & $\begin{array}{c}21 / 12 / 12 \\
18: 00\end{array}$ & $\begin{array}{c}179.3 \\
4\end{array}$ & $\begin{array}{c}320.8 \\
1.3\end{array}$ & --.- & $\begin{array}{c}248.7 \\
4\end{array}$ & $\begin{array}{c}319.2 \\
1.8\end{array}$ & --- & $\begin{array}{c}169.7 \\
4\end{array}$ & $\begin{array}{c}312.5 \\
1.4\end{array}$ & --- \\
\hline $\begin{array}{c}\text { D21 } \\
\text { (End) }\end{array}$ & $\begin{array}{c}22 / 12 / 12 \\
09: 00\end{array}$ & $\begin{array}{c}84.8 \\
4\end{array}$ & $\begin{array}{c}298.5 \\
2.7\end{array}$ & $\begin{array}{l}-94.5 \\
105.4 \\
-22.3\end{array}$ & $\begin{array}{c}106.7 \\
4\end{array}$ & $\begin{array}{c}295.6 \\
2.2\end{array}$ & $\begin{array}{c}-142.0 \\
160.6 \\
-23.6\end{array}$ & $\begin{array}{c}67.3 \\
4 \\
\end{array}$ & $\begin{array}{c}246.9 \\
3.4 \\
\end{array}$ & $\begin{array}{c}-102.4 \\
165.8 \\
65.6\end{array}$ \\
\hline
\end{tabular}


2 Table 3 Areas of the buoy arrays on August 14 (17:00 UTC), December 14 (09:00

3 UTC), December 17 (09:00 UTC), and December 22 (09:00 UTC). The areas on

4 August 14 represent the initial state right after the deployment. The areas on

5 December 14, 17 and 22 represent the state after each deformation event. $\sigma_{\mathrm{A}}$ is the

6 error estimates for each buoy array (see text for the details). $\Delta \mathrm{A}$ is the change of

7 area before and after each deformation event. Any $\Delta A$ values above the error $\sigma_{A}$ are

8 valid. Note some of $\Delta \mathrm{A}$ becomes smaller or comparable to $\sigma_{\mathrm{A}}$.

\begin{tabular}{|c|c|c|c|c|c|c|}
\hline \multirow[t]{2}{*}{ Date } & \multicolumn{2}{|c|}{$\begin{array}{c}\text { A } \\
\text { SI04-KP08-KP04 } \\
\text { Half FYI and MYI }\end{array}$} & \multicolumn{2}{|c|}{$\begin{array}{c}\text { B } \\
\text { SI04-KP08-KP03 } \\
\text { Predominately FYI } \\
\end{array}$} & \multicolumn{2}{|c|}{$\begin{array}{c}\text { C } \\
\text { SI04-KP03-KP04 } \\
\text { Half FYI and MYI }\end{array}$} \\
\hline & $\begin{array}{c}A\left(m^{2}\right) \\
\sigma_{A}\end{array}$ & $\begin{array}{c}\Delta A \\
\left(m^{2} \text { and } \%\right)\end{array}$ & $\begin{array}{c}\mathbf{A}\left(\mathbf{m}^{2}\right) \\
\sigma_{\mathrm{A}}\end{array}$ & $\begin{array}{c}\Delta \mathrm{A} \\
\left(\mathrm{m}^{2} \text { and } \%\right)\end{array}$ & $\begin{array}{c}A\left(m^{2}\right) \\
\sigma_{A}\end{array}$ & $\begin{array}{c}\Delta \mathrm{A} \\
\left(\mathrm{m}^{2} \text { and } \%\right)\end{array}$ \\
\hline Aug 14 & $\begin{array}{r}4797 \\
478\end{array}$ & --- & $\begin{array}{c}3684 \\
398\end{array}$ & --- & $\begin{array}{l}579 \\
536\end{array}$ & --- \\
\hline Dec 14 & $\begin{array}{c}3575 \\
574\end{array}$ & $-1222(-26 \%)$ & $\begin{array}{c}1772 \\
472\end{array}$ & $-1912(-52 \%)$ & $\begin{array}{c}1136 \\
577\end{array}$ & 557 (96\%) \\
\hline Dec 17 & $\begin{array}{c}2364 \\
604\end{array}$ & $-1211(-51 \%)$ & $\begin{array}{l}495 \\
502\end{array}$ & $-1277(72 \%)$ & $\begin{array}{c}1738 \\
609\end{array}$ & $602(53 \%)$ \\
\hline Dec 22 & $\begin{array}{c}2697 \\
252\end{array}$ & 333 (14\%) & $\begin{array}{c}2236 \\
216\end{array}$ & $1741(352 \%)$ & $\begin{array}{l}229 \\
272\end{array}$ & $-1509(-86 \%)$ \\
\hline Total & --- & $-2100(-44 \%)$ & --- & $-1448(-39 \%)$ & --- & $-350(-61 \%)$ \\
\hline
\end{tabular}

9 


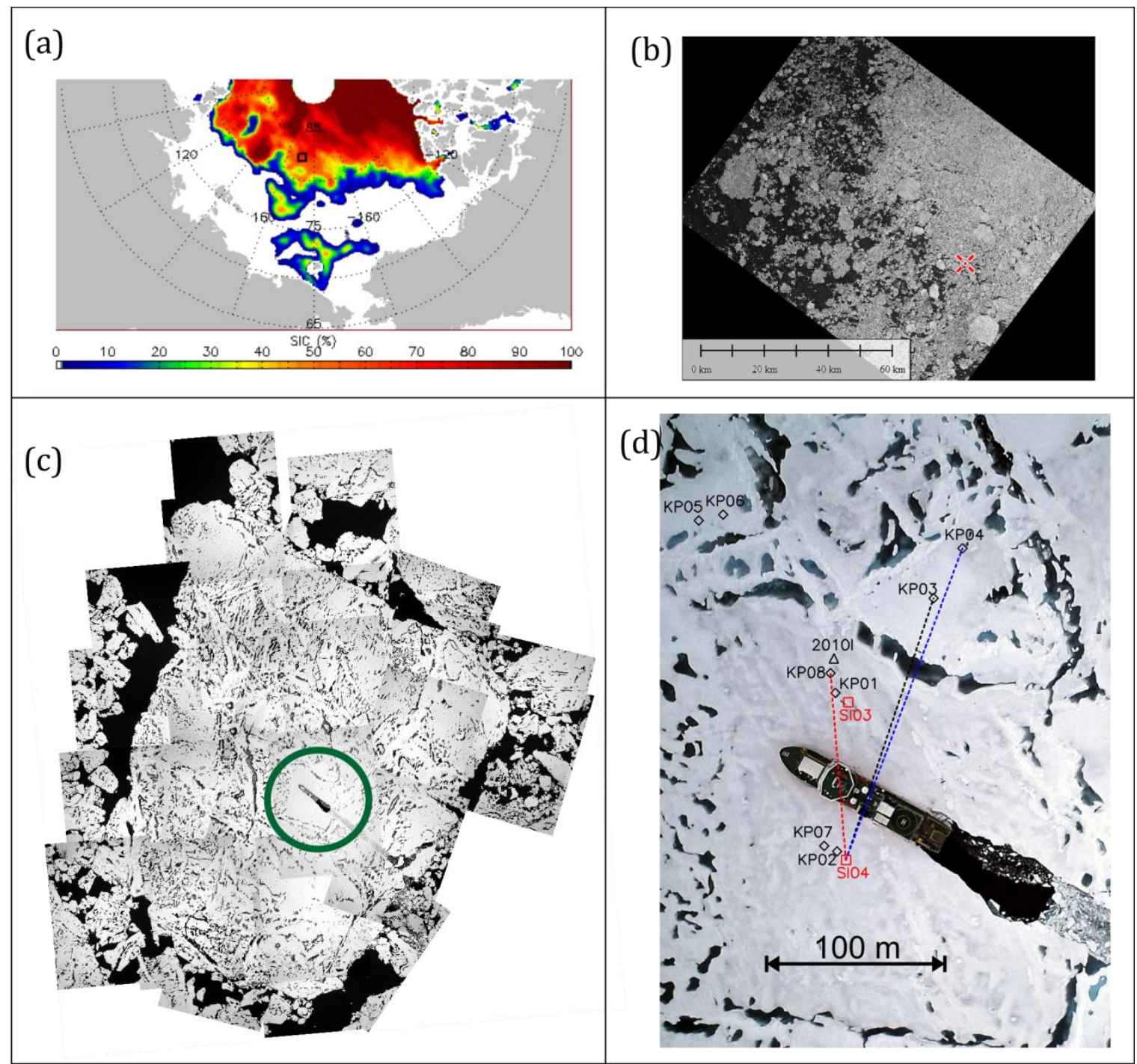

3 Figure 1 (a) Sea ice concentration during the buoy deployment, on 14 August 2012, 4 with deployment location marked as a black rectangular box. (b) TerraSAR-X

5 ScanSAR image acquired on 29 August 2012 (15 days after deployment) with floe 6 location marked as a red diagonal crosshair symbol. (c) Aerial mosaic from photos

7 taken on 14 August 2012 but rotated to match the orientation of the floe on 15

8 August 2012 at 06:00 UTC. The green circle marks the location of IBRV Araon, which

9 is about 100-m long. (d) Zoom in with buoy locations overlaid on the aerial mosaic.

10 In the photo black, blue, and red dashed lines depict baselines to SI04 from KP03,

$11 \mathrm{KP} 04$, and KP08, respectively. In all panels, North (East) is direction to the top

12 (right). (See text for more details). 

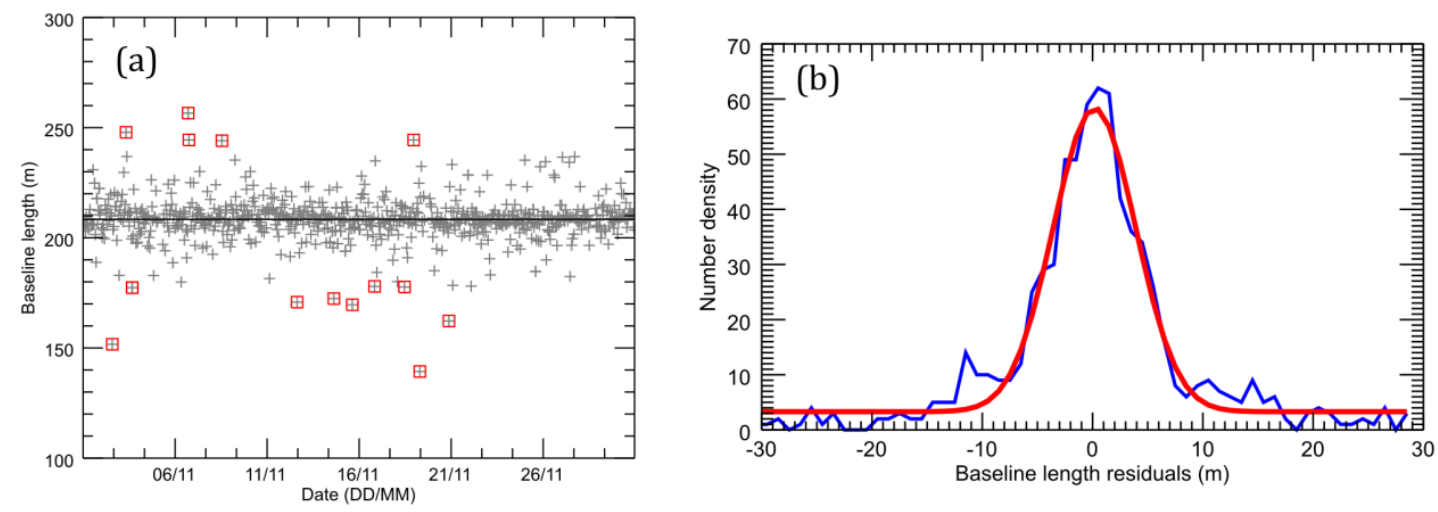

5 Figure 2 (a) Times series of SI04-KP04 baseline length estimates in November

6 2012, with highlighted (red squares) 3- $\sigma$ (standard deviation) outliers. Before and

7 after removing 3- $\sigma$ outliers the mean (and standard deviation) of the baseline length

8 were 208.4 $\pm 10.1 \mathrm{~m}(\mathrm{~N}=729)$ and 208.6 $\pm 8.3 \mathrm{~m} \mathrm{(N=714)}$, respectively. During this

9 period GPS sampling rate was 1 hour. (b) Number density histogram of the SI04-

10 KP04 baseline length residuals. The blue line is the data histogram of the data points

11 after removing 3- $\sigma$ outliers and the red line is the best Gaussian fit to the data. The

12 mean and standard deviation of the fitted Gaussian are $-0.2 \pm 3.7 \mathrm{~m}(\mathrm{~N}=714)$. 

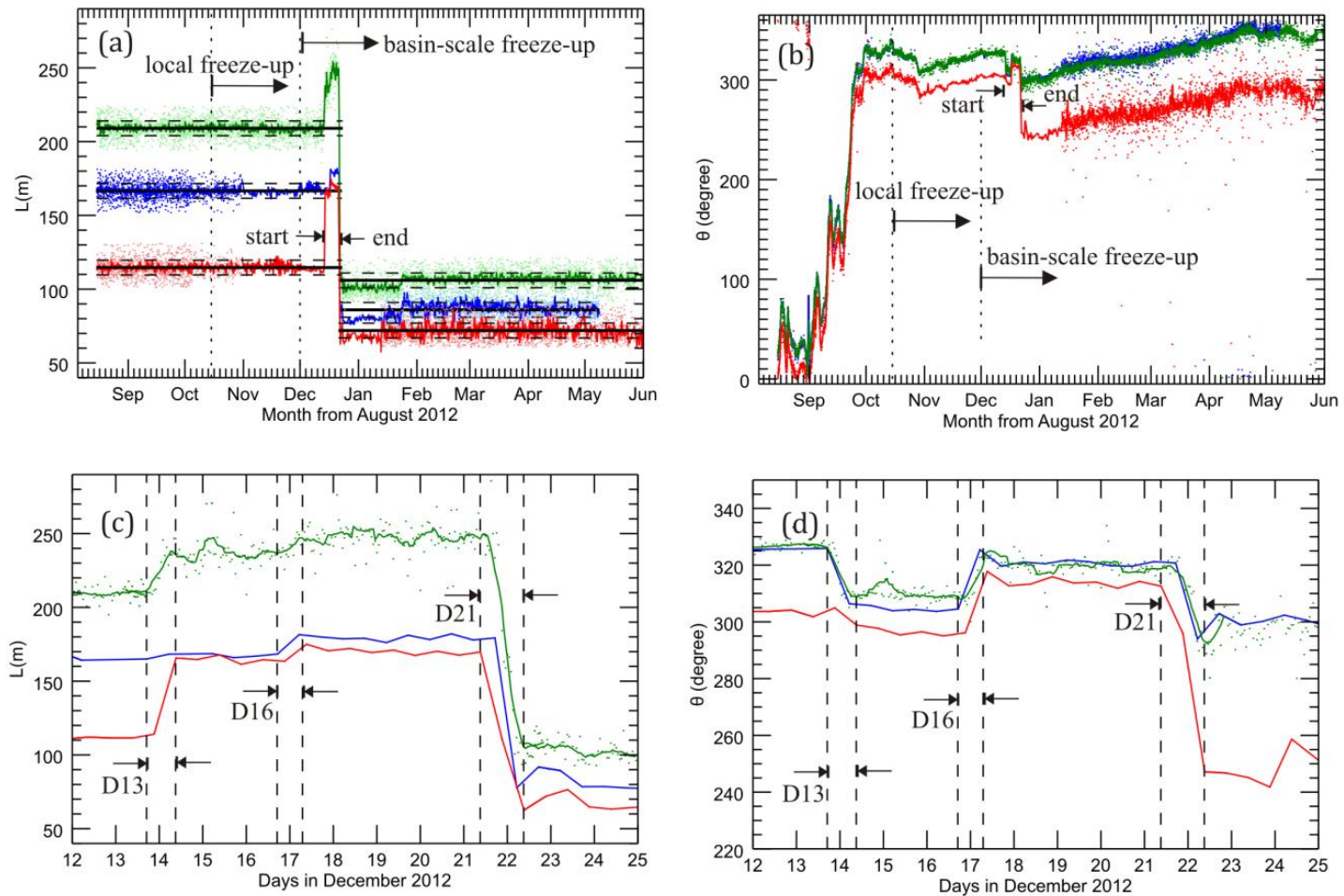

2 Figure 3 Time series of (a) baseline length $L$ and (b) orientation $\theta$ for the KP03

3 (blue), KP04 (green), and KP08 (red) baselines to SI04 from deployment in August

42012 through May 2013. In (a) and (c) the small dots are the position data and lines

5 are either data sampled twelve hourly or moving-averaged to 12 hours if the GPS

6 sampling rate was higher than 12 hours (see text). In (a), the black solid and dashed

7 lines are the average and one standard deviation, respectively, during the times of

8 no deformation. Vertical dotted line in (a) and (b) denotes the start of both local and

9 basin-scale freeze-up (see text). Panels (c) and (d) are the same as (a) and (b),

10 respectively, but here for December 2012 to zoom in on the deformation period.

11 Labels D13, D16, and D21 identify the three deformation events.

12 


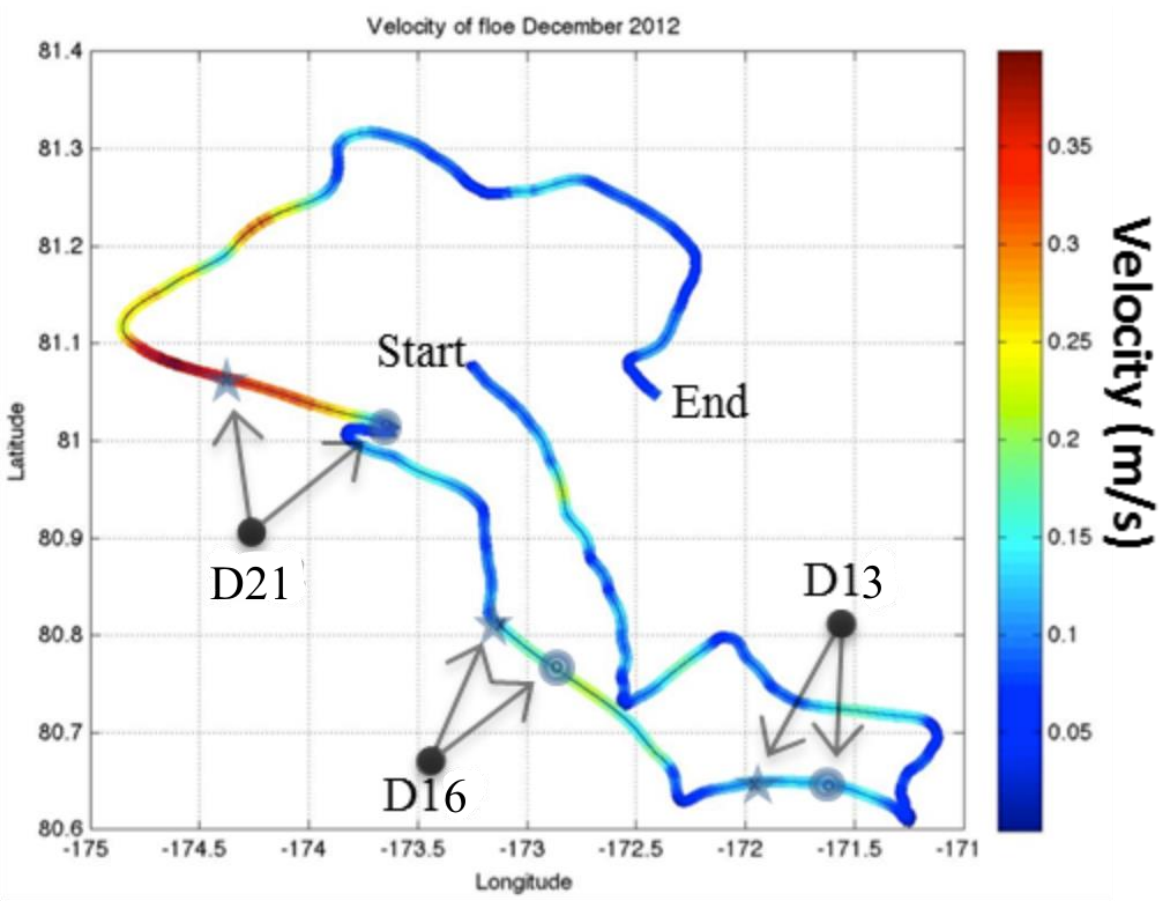

3 Figure 4 Drift track of the floe for the month of December 2012. The track is color4 coded for drift speed and the locations of these events (D13, D16, and D21) are also 5 displayed. Circle represents the start of a deformation event as seen by a change in 6 baseline distance, and a star represents the finish of an event as seen by the baseline 7 length remaining constant. 

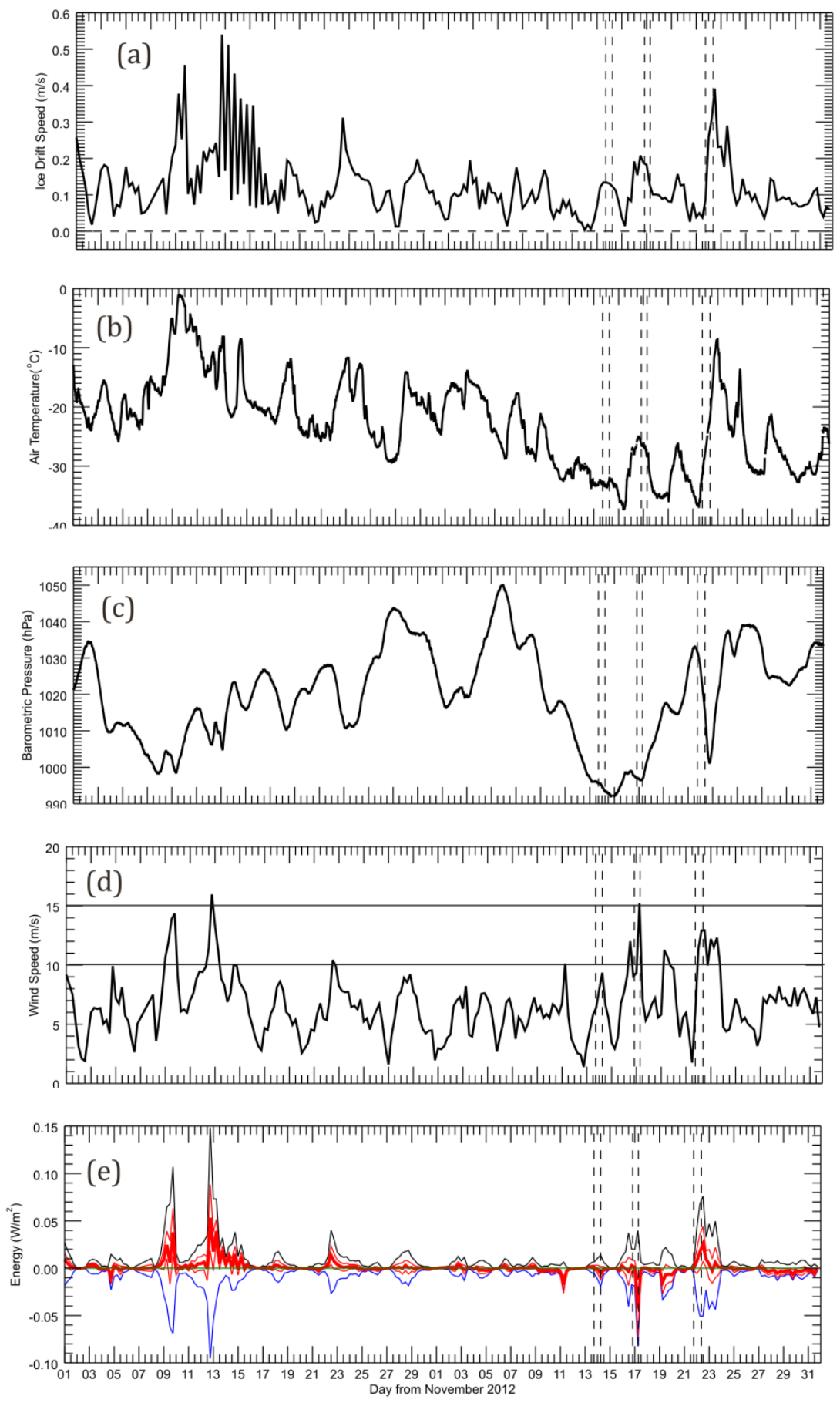

2 Figure 5 Temporal variation of (a) ice drift speed, (b) air temperature, (c)

3 barometric pressure, (d) wind speed, and (e) kinetic energy of $U \times F_{a}$ (black), $U_{m} \times F_{a}$

4 (blue) and $U^{\prime} \times F_{a}$ (red), during November and December 2012. Vertical dashed lines

5 denote the times of the D13, D16, and D21 deformation events. (See text for the

6 definition of kinetic energy.) 

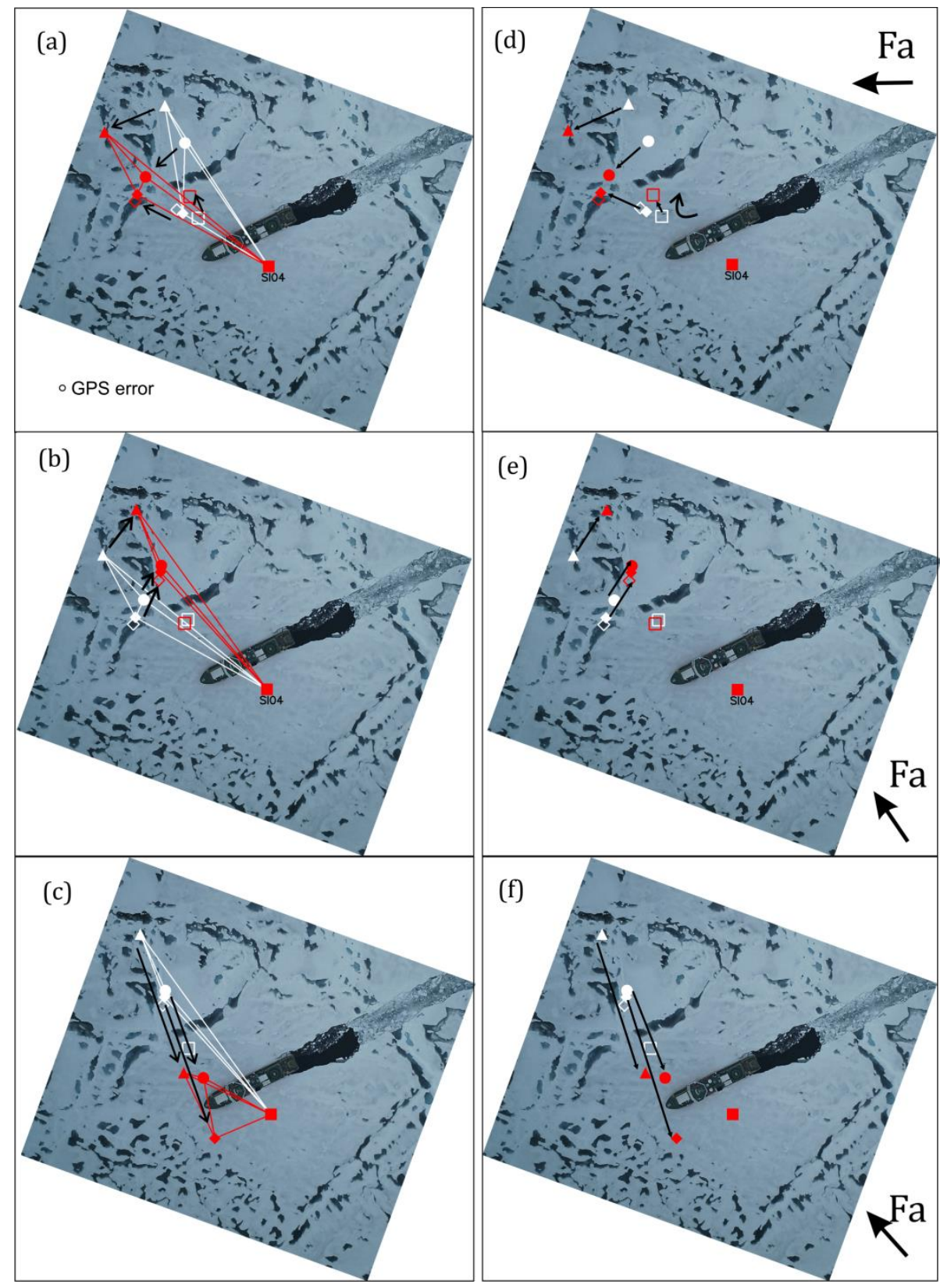

2 Figure 6 Deformation of buoy arrays during the (a)\&(d) D13, (b)\&(e) D16, and

3 (c)\&(f) D21 events. In the left panels, the white and red lines represent the buoy

4 arrays before and after the events, respectively. In all panels, black solid arrows

5 show displacement relative to SI04. Closed square, circle, triangle, and diamond

6 symbols mark the locations of SI04, KP03, KP04 and KP08, respectively, and open

7 square and diamond symbols for that of SI03 and 2010I, respectively. $\mathrm{F}_{\mathrm{a}}$ is the

8 direction of wind stress. The aerial photography and buoy arrays of August 14

9 (Figure 1) here rotated for the floe orientation on December 13. Black circle in (a) is

10 the IMB GPS error estimate ( $4 \mathrm{~m}$ ), drawn to scale. 


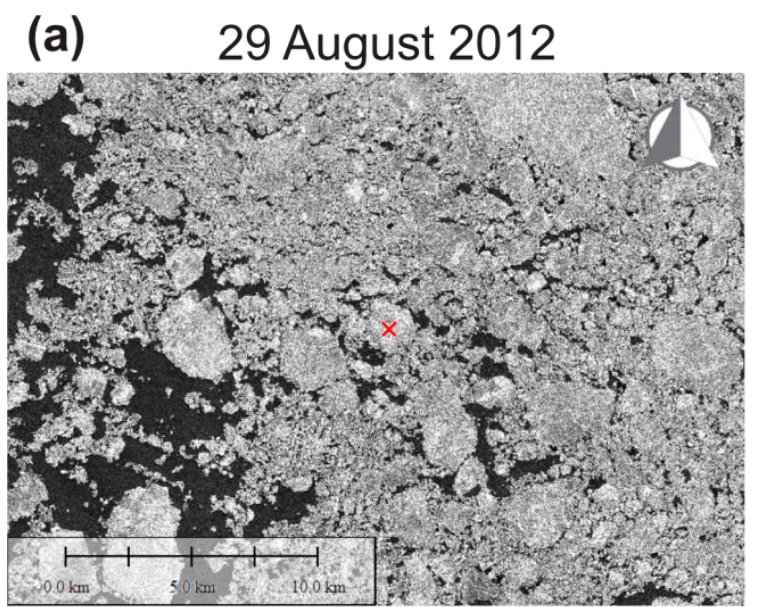

(c) 25 October 2012

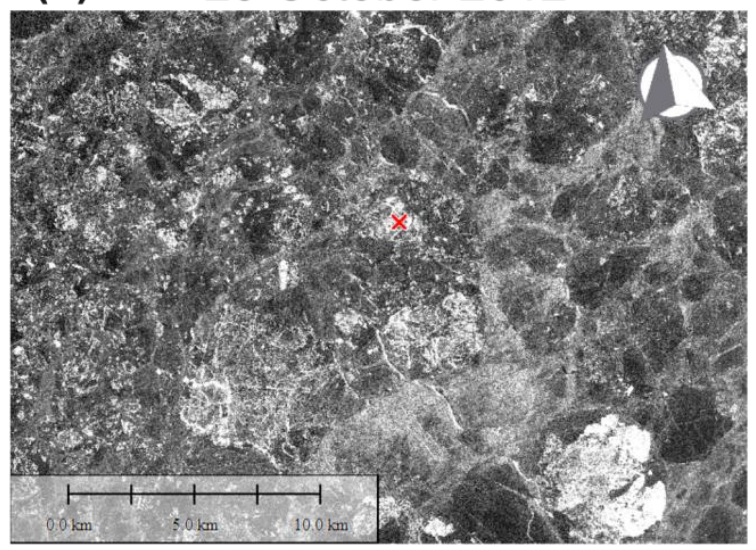

(b) 02 October 2012

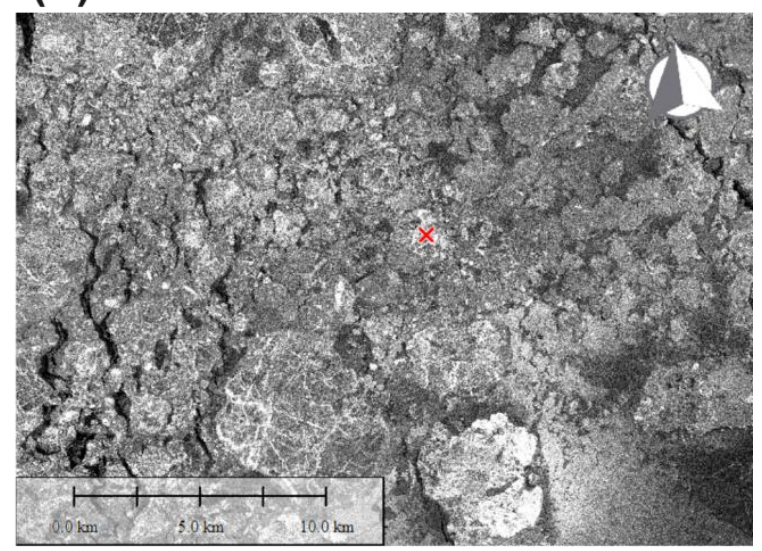

(d) 16 January 2013

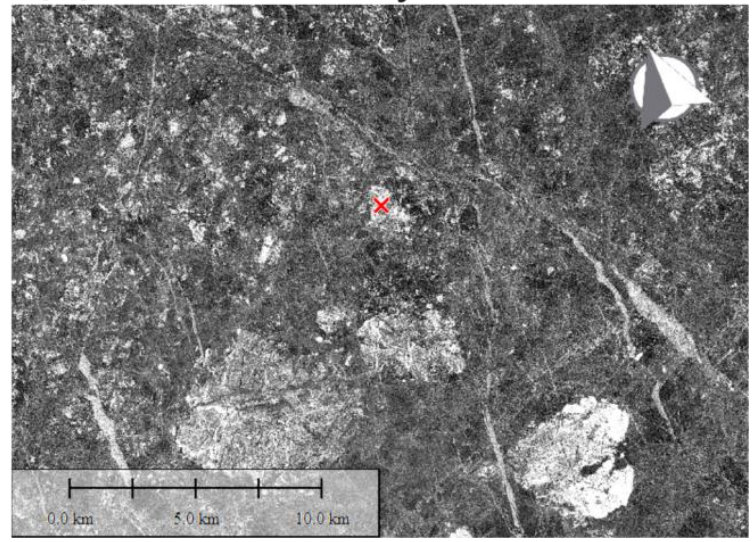

4 Figure 7 TerraSAR-X ScanSAR image (CDLR) acquired on (a) 29 August 2012, (b) 2

5 October 2012, (c) 25 October 2012, and (d) 16 January 2013. The location of the ice

6 floe is marked as red $x$ in the middle of each image. The spatial scale of the image is

7 shown on the bottom left and a compass on the top right corner of each image. Each

8 image covers an area of 35 by $35 \mathrm{~km}$. In the image, grey tone indicates the strength

9 of backscattering, i.e., darker tone is low backscattering and brighter tone is high

10 backscattering. For example, calm open water is shown in black dark tone, and

11 multiyear ice floes in much brighter tone.

12

13

14 

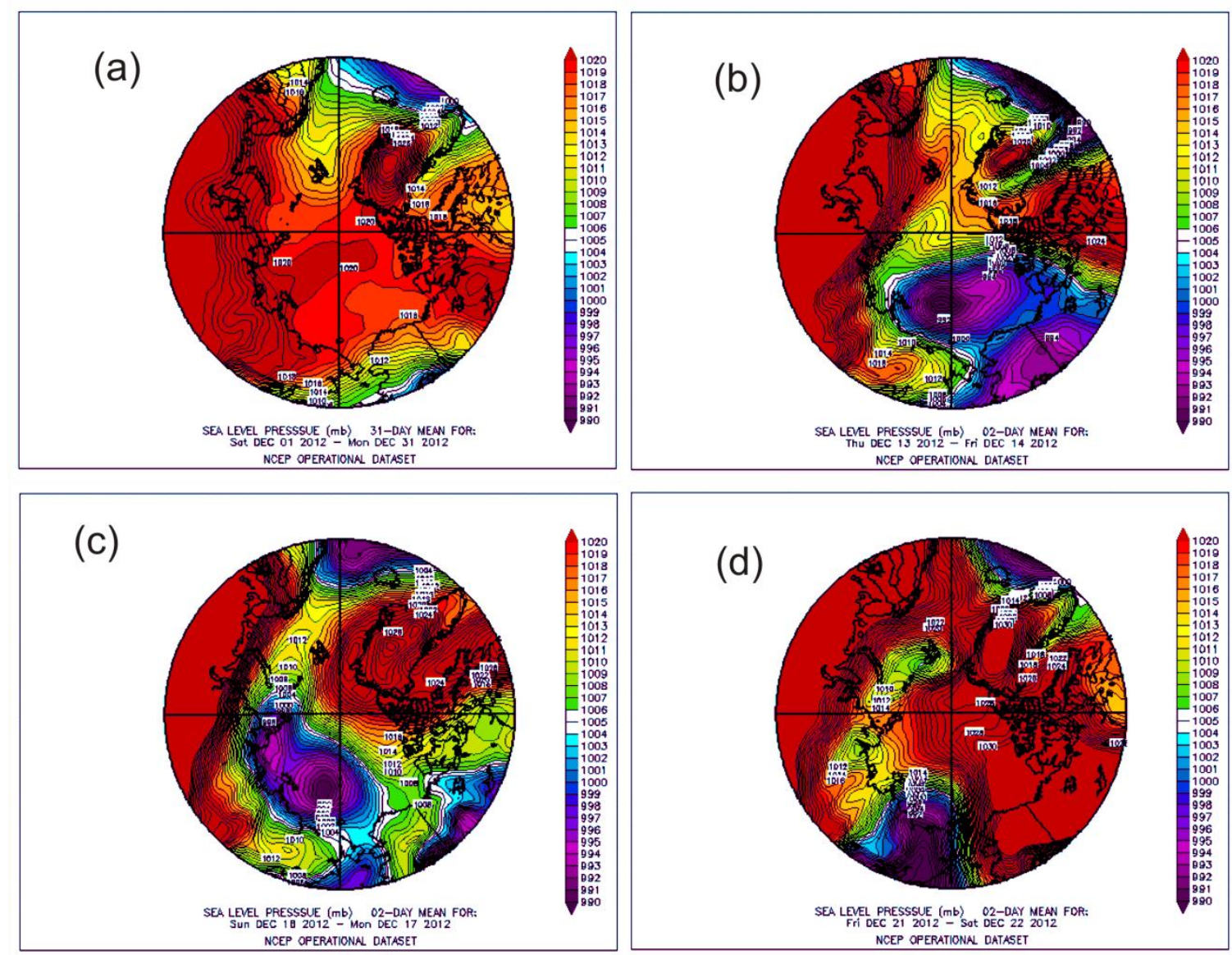

3 Figure 8 Sea level pressure maps (a) during December 2012, (b) on December 13,

4 (c) on December 17, and (d) on December 21. The plots were created from the NCEP 5 Operational Plotting Page (http://www.esrl.noaa.gov/psd/data/histdata/). 

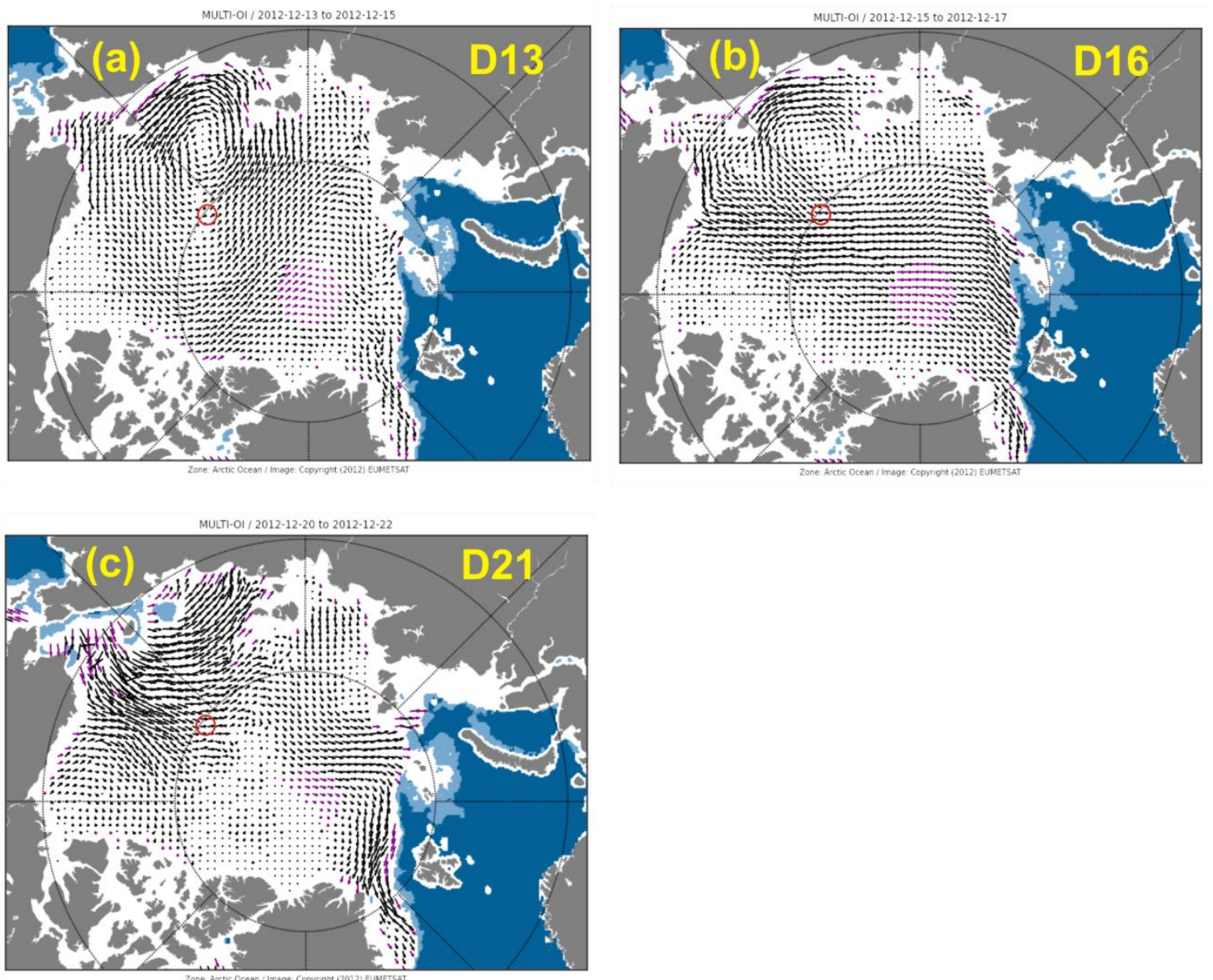

3 Figure 9 Satellite ice drift maps during the three deformation events, (a) D13, (b) 4 D16, and (c) D21. The images were downloaded from EUMETSAT's Ocean and Sea 5 Ice (OSI) Satellite Application Facility (SAF) High Latitude (HL) Processing Centre 6 (http://osisaf.met.no/). 

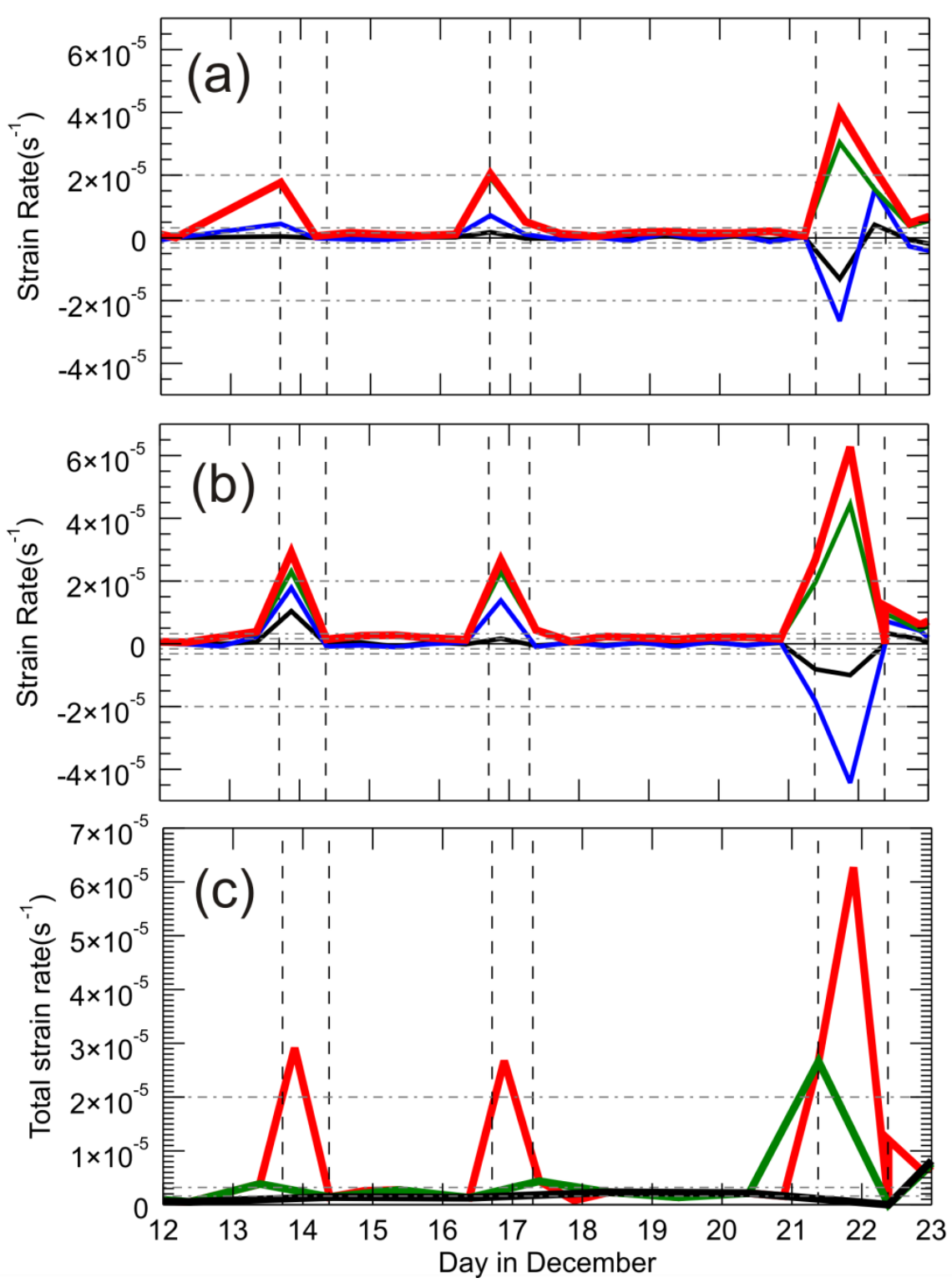

2 Figure 10 Strain rates calculated from the pair of (a) SI04-KP03 and (b) SI04-KP08

3 for the 12-h time scale. In (a) and (b) solid black, blue, green, and red lines are strain

4 rates estimated from baseline length $\left(\varepsilon_{\mathrm{L}}\right)$, divergence $\left(\varepsilon_{\mathrm{d}}\right)$, shear $\left(\varepsilon_{\mathrm{S}}\right)$, and total

5 deformation $\left(\varepsilon_{\mathrm{t}}\right)$. In (c) total strain rates $\left(\varepsilon_{\mathrm{t}}\right)$ of SI04-KP08 are shown for the time

6 scale of 12 hours (red line), 1 day (green line), and 2 days (black line). In all plots

7 three thin horizontal (grey) dash-dot lines are the error estimates for the strain rate

8 for the time scale of 1 hour, 6 hours and 9 hours (see text). The error lines for the

9 time scale of 1 hour are furthest from the zero, and the ones for the time scale of 9

10 hours are closest to zero. 


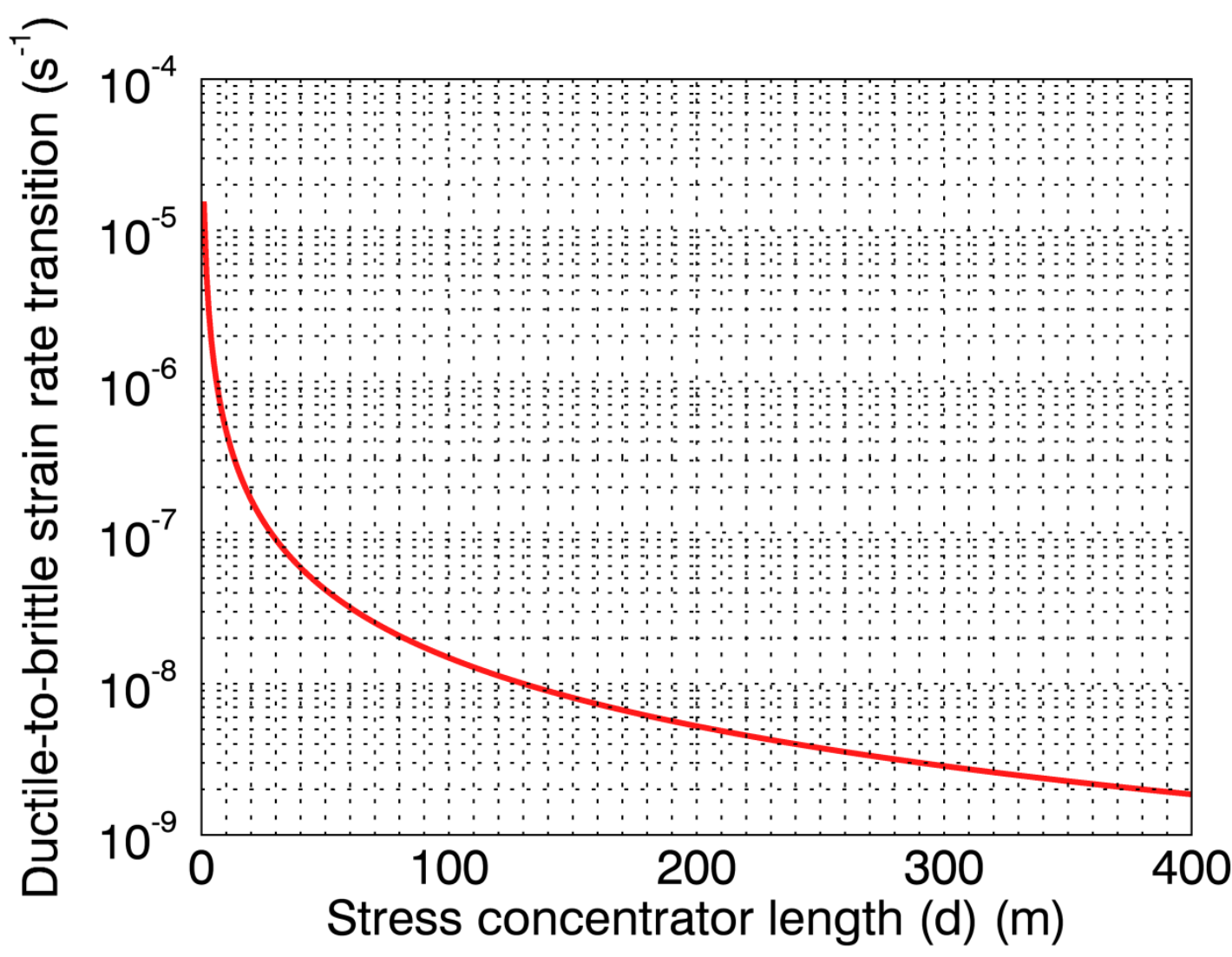

3 Figure 11 Ductile-to-brittle strain rate transition as a function of the length of stress

4 concentrators (crack/lead) d. The strain rate transition was calculated from Eq. 21

5 in Schulson (2001) using the same values for all model parameters but with d

6 varying between 0 and $400 \mathrm{~m}$. 


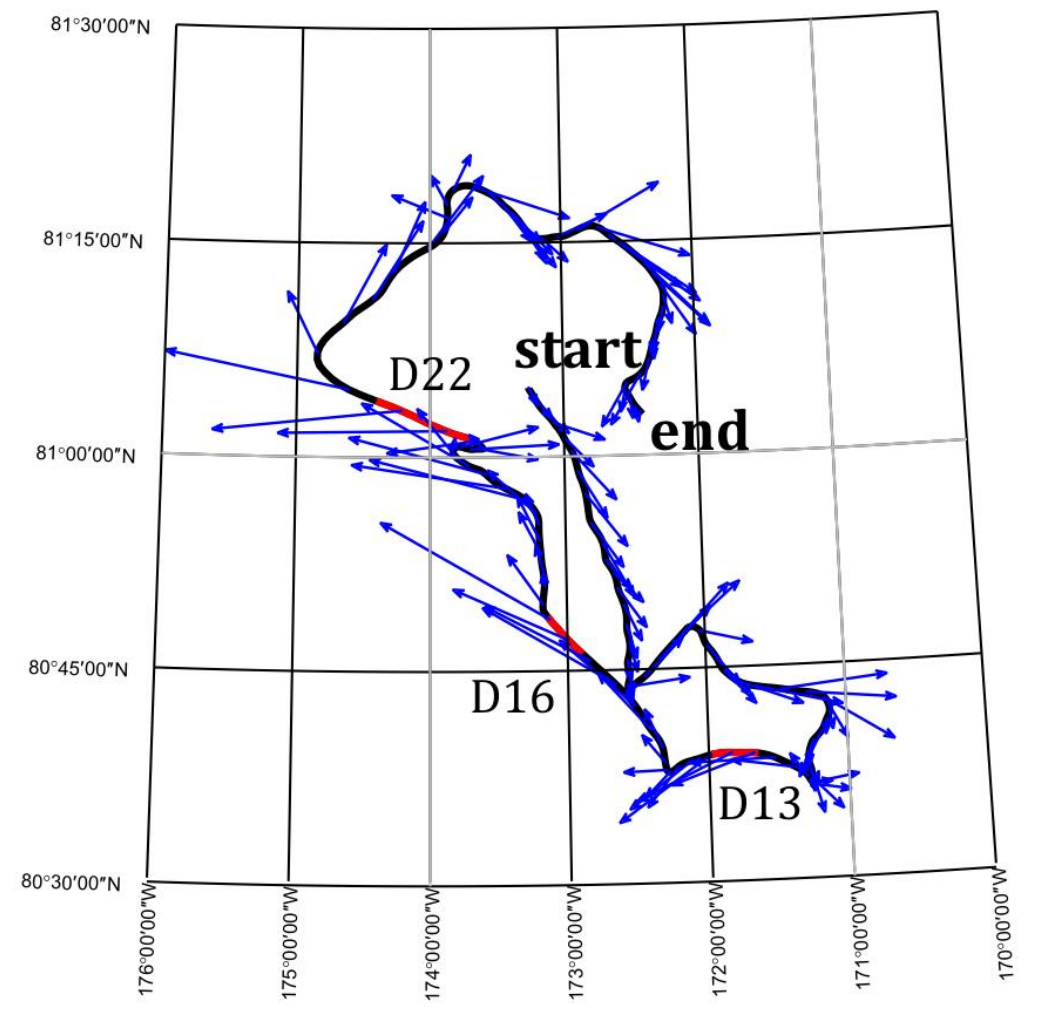

1

2 Figure 12 Wind vectors along the drift track of the floe. The three deformation 3 periods are highlighted in red in the drift track. 4 
(a) 25 October 2012

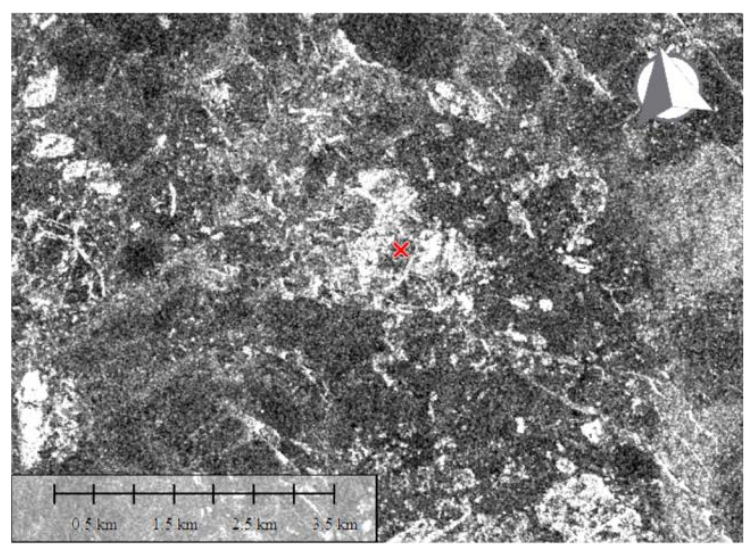

(b) 23 December 2012

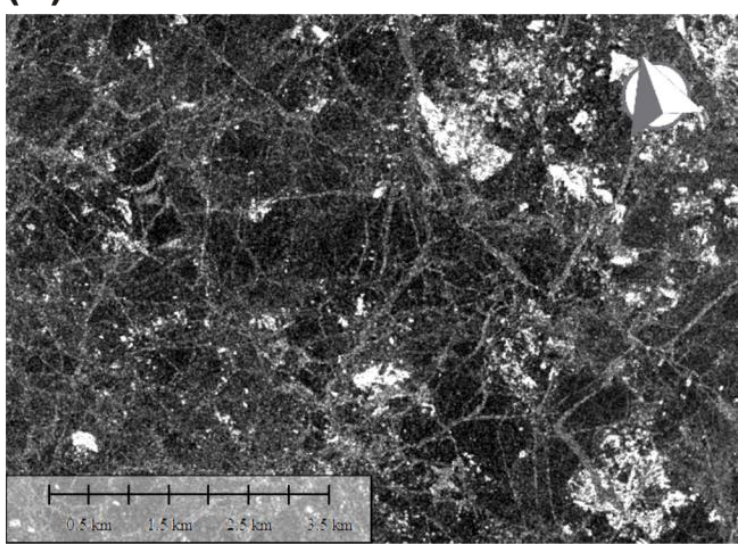

4 Figure 13 TerraSAR-X ScanSAR image (CDLR) acquired on (a) 25 October 2012

5 amd (b) 23 December 2012. The images cover the area of $7 \mathrm{~km}$ by $10 \mathrm{~km}$, and red $\mathrm{x}$

6 mark in (a) indicates the location of SI04 at the time of image taken. The December

723 image shows the area about $30 \mathrm{~km}$ from the buoy location (no image available at

8 the buoy location on that day). The spatial scale of the image is shown bottom left

9 and compass in the top right corner of each image. In the image grey tone indicates

10 the strength of backscattering, i.e., darker tone is low backscattering and brighter

11 tone is high backscattering. In (b) darker grey tone indicates young growing ice and

12 thin lines of brighter tone are the fracture lines. Multiyear ice floes are shown in

13 much brighter tone. 